\title{
Novel Layered and 2D Materials for Functionality Enhancement of Contacts and Gas Sensors
}

\author{
Hossein Fashandi
}

\section{0.}

\author{
Applied Physics Division \\ Department of Physics, Chemistry, and Biology (IFM) \\ Linköping University \\ SE-581 83 Linköping, Sweden
}


The cover image shows partial intercalation of gold (in yellow) into $\mathrm{Ti}_{3} \mathrm{SiC}_{2}$ observed by scanning transmission electron microscopy; a result from my research.

During the course of research underlying this thesis, I was enrolled in Agora Materiae, a multidisciplinary doctoral program at Linköping University, Sweden.

(C)Hossein Fashandi

ISBN: 978-91-7685-699-4

ISSN: 0345-7524

Printed by LiU-Tryck

Linköping 2016 
To Elham 


\section{Abstract}

Chemical gas sensors are widely-used electronic devices for detecting or measuring the density levels of desired gas species. In this study, materials with established or potential applications for gas sensors are treated. For the case of high-temperature applications $\left(\approx 600{ }^{\circ} \mathrm{C}\right)$, semiconductor-based gas sensors suffer from rapid oxidation of the metallic ohmic contacts, the same cause-of-failure as for the general case of high-temperature semiconductor electronics. $4 \mathrm{H}-\mathrm{SiC}$ is an ideal semiconductor for high-temperature applications. $\mathrm{Ti}_{3} \mathrm{SiC}_{2}$ is a known ohmic contact to $4 \mathrm{H}-\mathrm{SiC}$ with the known two-step synthesis process of post-annealing of pre-deposited Ti/Al multilayers or sputterdeposition of $\mathrm{Ti}_{3} \mathrm{SiC}_{2}$ films at $>900{ }^{\circ} \mathrm{C}$. Here, sputter-deposition of $\mathrm{Ti}$ on $4 \mathrm{H}-\mathrm{SiC}$ at $>$ $900{ }^{\circ} \mathrm{C}$ is presented as a novel single-step method for the synthesis of $\mathrm{Ti}_{3} \mathrm{SiC}_{2}$ ohmic contacts, based on a concurrent reaction between sputter-deposited $\mathrm{Ti}$ and $4 \mathrm{H}-\mathrm{SiC}$. $\mathrm{Ti}_{3} \mathrm{SiC}_{2}$, similar to any other known ohmic contact, degrades rapidly in high-temperature oxidizing ambient. To try to overcome this obstacle, noble-metal diffusion into $\mathrm{Ti}_{3} \mathrm{SiC}_{2}$ has been studied with the goal to retain ohmic properties of $\mathrm{Ti}_{3} \mathrm{SiC}_{2}$ while taking advantage from the oxidation resistivity of noble metals. A novel exchange intercalation between $\mathrm{Ti}_{3} \mathrm{SiC}_{2}$ and $\mathrm{Au}$ is discovered which results in almost complete exchange of $\mathrm{Si}$ with $\mathrm{Au}$ giving rise to novel $\mathrm{Ti}_{3} \mathrm{AuC}_{2}$ and $\mathrm{Ti}_{3} \mathrm{Au}_{2} \mathrm{C}_{2}$. $\mathrm{Ti}_{3} \mathrm{IrC}_{2}$ is also synthesized through exchange intercalation of $\mathrm{Ir}$ into $\mathrm{Ti}_{3} \mathrm{Au}_{2} \mathrm{C}_{2}$. All the aforementioned phases showed ohmic properties to $4 \mathrm{H}-\mathrm{SiC}$. This technique is also studied based on $\mathrm{Ti}_{2} \mathrm{AlC}$ and $\mathrm{Ti}_{3} \mathrm{AlC}_{2}$ resulting in the synthesis of novel $\mathrm{Ti}_{2} \mathrm{Au}_{2} \mathrm{C}$ and $\mathrm{Ti}_{3} \mathrm{Au}_{2} \mathrm{C}_{2}$, respectively. Using $\mathrm{Ti}_{3} \mathrm{AuC}_{2}$ and an $\mathrm{IrO}_{\mathrm{x}} / \mathrm{Au}$ capping layer, an ohmic contact was manufactured which maintained ohmic properties and showed no structural defects after $1000 \mathrm{~h}$ of aging at $600{ }^{\circ} \mathrm{C}$ air.

$\mathrm{Ti}_{3} \mathrm{SiC}_{2}$ is a member of a large family of materials known as $\mathrm{M}_{\mathrm{n}+1} \mathrm{AX}_{\mathrm{n}}$ phases. While exchange reactions of $\mathrm{Si}$ (or $\mathrm{Al}$ ) planes $\mathrm{inTi}_{3} \mathrm{SiC}_{2}\left(\mathrm{Ti}_{2} \mathrm{AlC}\right.$ and $\left.\mathrm{Ti}_{3} \mathrm{AlC}_{2}\right)$ is presented here, a world-wide research already exists on chemical removal of the same atomic planes from different $M_{n+1} A X_{n}$ phases and the synthesis of $M_{n+1} X_{n}$ sheets known as MXenes. I performed a theoretical study regarding simulation of electronic and structural properties of more than120 different possible MXene phases. The results show that some MXene phases when terminated by particular gas species turn into Dirac materials, i.e., they possess massless Dirac fermions close to the Fermi level. Compared to graphene, they possess a higher number of Dirac points, giant spin orbit splitting, and preserved 2D-type 
electronic properties by extending the dimensionality. The general substantial change of the electronic properties of MXenes under different gas adsorption configurations stands out and can thus be harnessed for sensing applications.

Growth of monolayer iron oxide on porous Pt sensing layers is another novel approach used in this study for applying the unique properties of $2 \mathrm{D}$ materials for gas sensors. A low temperature shift in $\mathrm{CO}$ oxidation characteristics is presented as compared to bare $\mathrm{Pt}$. The approach is similar to that previously reported using bulk single-crystal Pt substrate, the latter being an unrealistic model for sensors and catalysts. Monolayer-coated Pt sensing layers were fabricated as the metal component of a metal oxide semiconductor (MOS) capacitor device, whereby the electrical response of the MOS device could be used to map out the catalytic properties of the sensing layer. The monolayer-coated $\mathrm{Pt}$ surface showed to be stable with retained improved catalytic properties for $>200 \mathrm{~h}$. The MOS device approach is not only used for in-situ monitoring of the surface chemical properties of the monolayer-coated $\mathrm{Pt}$ but is also introduced as a highly functional technique for in-situ characterization of catalytic surfaces. 


\section{Populärvetenskaplig sammanfattning}

Kemiska gassensorer är elektronisk mätutrustning som används för att upptäcka farliga gaser i vår omgivning. Användningsområdet spänner över kvalitetskontroll av inomhusluft, utsläppskontroll från industrier och fordon, prestandakontroll för förbränningsmotorer, jetmotorer, och så vidare. Ett exempel är kolmonoxidgivare som mäter i närheten av industri eller hushållspannor, alternativt reglerar processer i desamma, för att förhindra eventuella utsläpp av giftig och luktfri kolmonoxid.

Under de senaste decennierna har sensorvetenskap, inklusive applikationer inom industrin, genomgått en anmärkningsvärd utveckling. Det är i hög grad relaterat till framsteg inom materialvetenskap och annan teknik. Till exempel blev kiselkarbid tillgängligt som halvledarmaterial under 90-talet. Kiselkarbid, SiC, är ett mycket stabilt och kemiskt tåligt halvledarmaterial, som behåller sina egenskaper vid höga temperaturer där inga andra vanliga halvledare, som kisel eller germanium, kan användas. Numera utgör $\mathrm{SiC}$ basen för en högtemperaturelektronik som används till gassensorer. Ett exempel på sådana är sensorer som installeras i avgasröret i fordon för kontroll av utsläpp, varvid dessa under lång tid måste klara en temperatur på $600{ }^{\circ} \mathrm{C}$.

Ett annat exempel på viktiga framsteg inom materialvetenskapen är upptäckten av materialet grafen. Detta utgörs av ett tvådimensionellt (2D) nät av kolatomer och introducerades för första gången för bara ungefär ett decennium sedan (2004) och dessutom resulterade det $\mathrm{i}$ ett Nobelpris 2010. För närvarande finns det många olika tillämpningar som rapporterats baserat på de unika egenskaperna hos grafen, såsom hög ledningsförmåga, det är extremt starkt och ogenomträngligt för de flesta molekyler. En av de intressanta tillämpningarna av grafen är ultrakänsliga gassensorer där grafen utgör känselskiktet.

Studier inom materialvetenskap kan delas in i två näraliggande delar, teoretiska och experimentella studier. Teoretiska studier kompletterar experimentella insatser via simuleringar som möjliggör förutsägelser och förklaringar av materialegenskaper. Teoretiska studier hjälper därför till att förstå beteendet hos material under olika förhållanden. Under mina doktorandstudier studerade jag olika material i syfte att 
förbättra funktionen hos gassensorer, varvid jag använde en kopplad teoretiskexperimentell metod.

Mina studier ledde till att jag upptäckte några helt nya material. De består av titan, kol och ädelmetaller, såsom $\mathrm{Ti}_{3} \mathrm{Au}_{2} \mathrm{C}_{2}$ (förening med tre titan, två guld och två kol) eller $\mathrm{Ti}_{3} \mathrm{IrC}_{2}$ (tre titan, en iridium och två kol). En unik egenskap hos dem uppenbarades när jag använde dem som elektriska ohmiska kontakter till kiselkarbid. En ohmisk kontakt är ett (oftast) metalliskt material som odlas på kiselkarbid eller någon annan halvledare, och gör att den kan anslutas till externa ledningar utan att ändra materialets karaktäristik. Nästan alla kända kontakter till kiselkarbid, gjorda av olika material, dör efter några timmar på grund av oxidation när de placeras vid höga temperaturer $\left(\approx 600^{\circ} \mathrm{C}\right)$, vilket hindrar användningen av materialen vid dessa höga temperaturer. Baserat på mina nya upptäckter, kan jag tillverka en kontakt som förblev helt intakt i 1000 timmar vid $600{ }^{\circ} \mathrm{C}$ i luft. Hemligheten är att täcka kontakten med ett skikt, till exempel iridiumoxid, som stänger ute syret i luften.

Jag har också studerat ett antal 2D material för gassensorer. Jag studerade funktionaliteten hos ett 2D-lager (monolager) av järnoxid när detta beläggs på ett vanligt förekommande platinaskikt, som används i gassensorer. Mina studier visar att detta 2D-järnoxidskikt förbättrar sensoregenskaperna så att kolmonoxid oxiderar på sensorytan vid $40{ }^{\circ} \mathrm{C}$ lägre temperatur. Dessutom har jag simulerat egenskaperna hos en annan grupp av 2D material som kallas MXene (uttalas, "maxen"). De är 2D-lager av metallkarbider som Ti2C eller $\mathrm{Zr3C}$ 2. Jag kunde teoretiskt förutsäga att en grupp av MXene-material är extremt känsliga för en viss typ av gaser som adsorberar på MXene-ytorna och är därför mycket lovande för sensortillämpningar. 


\section{Preface}

This research started in March 2012 and has been performed within Functional Nanoscale Materials Centre (FUNMAT), one of 19 VINN Excellence Centres initiated by the Swedish Agency for Innovation Systems (VINNOVA), with the main focus on new nanoscale sensor materials and applications (Theme 5 within FUNMAT). The introduction part of this thesis is largely based on my Licentiate thesis published in 2015 entitled "Functional Nanostructures for Gas Sensors", (thesis No. 1705). The corresponding activities have been performed at Linköping University, Department of Physics, Chemistry, and Biology (IFM) within the divisions of Applied Sensor Science, Thin Film Physics, and Theoretical Physics. The theoretical calculations has been performed using supercomputers provided by the Swedish National Infrastructure for Computing (SNIC) at the National Supercomputer Centre (NSC). In addition, I had external collaborations with the divisions of Material Physics and Microelectronics as well as Applied Physics at the Royal Institute of Technology, KTH and Institute for Molecules and Materials, Radboud University of Nijmegen, The Netherlands. 


\section{Included papers and comments on my contributions}

\section{Paper 1}

Single-step synthesis process of $\mathrm{Ti}_{3} \mathrm{SiC}_{2}$ ohmic contacts on $4 \mathrm{H}-\mathrm{SiC}$ by sputterdeposition of $\mathrm{Ti}$

Scripta Materialia, 99, 53-56, 2015

H. Fashandi, M. Andersson, J. Eriksson, J. Lu, K. Smedfors, C.-M. Zetterling, A. Lloyd Spetz, and P. Eklund

My contributions: I was involved in planning. I performed the depositions, XRD, SEM, EDX, and TEM sample preparations. I wrote the manuscript with P.E.

\section{Paper 2}

Noble-metal intercalation transformations of $\mathrm{Ti}_{3} \mathrm{SiC}_{2}$ into novel $\mathrm{Ti}_{3} \mathrm{AuC}_{2}, \mathrm{Ti}_{3} \mathrm{Au}_{2} \mathrm{C}_{2}$, and $\mathrm{Ti}_{3} \mathrm{IrC}_{2}$ phases for high-temperature-stable ohmic contacts to $\mathrm{SiC}$

\section{Submitted for publication}

Hossein Fashandi, Martin Dahlqvist, Jun Lu, Johanna Rosen, Lars Hultman, Mike Andersson, Anita Lloyd Spetz, and Per Eklund

My contributions: I was responsible for planning. I performed the depositions, annealing, SEM, and TEM sample preparations. I wrote the manuscript together with P.E and M.D.

\section{Paper 3}

Exchange-intercalation of gold into thin films of $\mathrm{Ti}_{2} \mathrm{AlC}$ and $\mathrm{Ti}_{3} \mathrm{AlC}_{2}$ leading to the formation of $\mathrm{Ti}_{2} \mathrm{Au}_{2} \mathrm{C}$ and $\mathrm{Ti}_{3} \mathrm{Au}_{2} \mathrm{C}_{2}$

\section{In Manuscript}

Hossein Fashandi, Chung-Chuan Lai, Martin Dahlqvist, Jun Lu, Johanna Rosen, Lars Hultman, Mike Andersson, Anita Lloyd Spetz, and Per Eklund

My contributions: I was responsible for planning, depositions, annealing, SEM, and TEM sample preparations. I wrote the manuscript. 


\section{Paper 4}

Dirac points with giant spin-orbit splitting in the electronic structure of two-dimensional transition-metal carbides

\section{Physical Review B, 92, 15, 155142}

Hossein Fashandi, Viktor Ivády, Per Eklund, Anita Lloyd Spetz, Mikhail I. Katsnelson, and Igor A. Abrikosov,

My contributions: I was responsible for initiating and planning the work. I performed the calculations related to band structure and density of states and wrote the corresponding parts in the article.

\section{Paper 5}

Applicability of MOS structures in monitoring catalytic properties as exemplified for monolayer-iron-oxide-coated porous platinum films

H. Fashandi, M. Soldemo, J. Weissenrieder, M.Götelid, J. Eriksson, P. Eklund, A. Lloyd Spetz, and M. Andersson

\section{Submitted for publication}

My contributions: I was involved in planning. I preformed the sensing measurements and wrote the manuscript together with M.A., with contributions from coauthors on the parts related to the photo electron spectroscopy and the monolayer synthesis process. 


\section{Acknowledgment}

I did my PhD at the Department of Physics, Chemistry, and Biology (IFM), Linköping University. Likewise many other multinational universities, the scientific atmosphere there was comprised of members with different backgrounds, levels, and experiences ranging from $\mathrm{PhD}$ students to highly cited world-wide-known scientists. The most important characteristic of that atmosphere though was that all those members were just colleagues with no hierarchy which imposed on me a valuable opportunity: "Learning by comparing different scientific characters of a wide range of different colleagues." Thus, I firstly would like to acknowledge the Swedish Academic Culture. I also appreciate every person who I had contact with at IFM because they fostered such an atmosphere. In particular, I appreciate

Per Eklund, my supervisor, for his endless patience and time for teaching and guidance and for the confidence and freedom he gave me to "play" science.

Anita Lloyd Spetz, my co-supervisor, for the opportunity to come to IFM and be a member of FUNMAT and Applied Sensor Science group.

Mike Andersson, my co-supervisor, for his help and $24 \times 7$ availability for my questions.

Lars Hultman, my co-supervisor, for his supports and his valuable contributions to interpreting and formulating our results.

Igor A. Abrikosov, for his kind encouragement, support, and guidance during the MXene project.

Jun Lu, for acting as the curious eye for my experiments in TEM labs.

Anne Henry, my mentor, for all her whole-hearted supports.

Per-Olof Holtz, for his supports as well as his kind efforts within Agora Materiae,

Viktor Ivady, my friend, for teaching me Bash and VASP.

Louise Gustafsson and Therese Dannetun, for all their kind administrative efforts.

Björgvin Hjörvarsson, my first supervisor in Sweden in Ångström lab while I was a research assistance, for the great opportunity to be a member of his group and all the valuable things I learned there.

and, Elham Mozafari, my lovely wife, for being the motivation for doing a $\mathrm{PhD}$, for her firm supports during my studies, for her being a kind teacher whenever I faced a problem in understanding physics or running a simulation, and for billions of her many kindnesses without which this thesis wouldn't have come true.

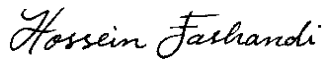




\section{Contents}

1. Introduction 1

1.1 $\mathrm{SiC}$ and its status for high-temperature gas-sensor applications 3

1.2 $\mathrm{M}_{\mathrm{n}+1} \mathrm{AX}_{\mathrm{n}}$ and MXene 4

$\begin{array}{lr}\text { 2. Ohmic Contacts } & 7\end{array}$

2.1 Ohmic contacts to $4 \mathrm{H}-\mathrm{SiC}$

$\begin{array}{ll}\text { 2.1.1 Ni-based ohmic contacts to 4H-SiC } & 10\end{array}$

$\begin{array}{ll}\text { 2.1.2 Ti-based ohmic contacts to } 4 \mathrm{H}-\mathrm{SiC} & 10\end{array}$

3. Thin Film Synthesis and Characterization 13

$\begin{array}{ll}3.1 \text { Synthesis } & 13\end{array}$

$\begin{array}{ll}3.2 \text { Characterization } & 16\end{array}$

$\begin{array}{ll}\text { 3.2.1 X-ray diffraction (XRD) analysis } & 16\end{array}$

$\begin{array}{ll}3.2 .2 \text { Electron microscopy } & 18\end{array}$

$\begin{array}{ll}\text { 3.2.3 Electrical transport measurements } & 23\end{array}$

$\begin{array}{lr}\text { 4. Intercalation } & 27\end{array}$

$\begin{array}{ll}\text { 4.1 Definition and Mechanisms } & 27\end{array}$

4.2 Thermal Synthesis of GICs 29

$\begin{array}{ll}4.3 \text { Applications } & 30\end{array}$

5. Theoretical Modeling 33

5.1 Many-body Schrödinger equation 33 
5.2 Kohn-Sham density functional theory (DFT)

5.3 Exchange-correlation Energy

5.4 KS self-consistent approach

6. Gas Sensors

6.1 Catalytic reactions and catalysis-based gas sensors 41

6.2 Field-effect gas sensors $\quad 42$

6.2 Characterization method 43

7. Contribution to the Field and Summary of the Papers 45

8. References $\quad 51$

9. Papers 


\section{Introduction}

This thesis is based on an experimental/theoretical approach towards the study of new materials and structures to be implemented in gas sensors. During the last decades, gas sensor science has experienced a remarkable growth which is mainly the result of two factors. Firstly, the advancements in materials science and engineering, e.g., production of commercial $\mathrm{SiC}$ wafers ${ }^{1}$ during the $90 \mathrm{~s}$, which is applicable in fabrication of gas sensors for high-temperature applications. ${ }^{2}$ Secondly, and probably the most influential, the growing need for gas detection in the market, e.g., in car industry ${ }^{3}$ and emission control. ${ }^{4}$ Gas sensor science, as any other market-related fields of research, is strongly related to its financial as well as practical aspects; in other words, the price and the functionality of each particular sensor device. In this area, detection of almost any kind of gas species can in theory be done using a mass spectrometer; an advanced device which detects the chemical nature of any materials in gaseous form introduced to it (see chapter 6). In practice, however, that device is not practical due to its high price, sophisticated use and maintenance, and limited functionality in different places and conditions mainly due to its size and delicacy, categorizing it as an advanced detection device for laboratories rather than a practical sensor. Nowadays chemical gas sensors can meet the aforementioned requirements. ${ }^{5}$ They are basic electronic devices as transistors, 
capacitors, or resistors, with their electric response being related to the concentration of one or a number of gas species in their immediate vicinity. The gas-sensitive component of this type of sensors is commonly a solid coating which can be a metal oxide, ${ }^{6}$ noble metal, ${ }^{7}$ or even a $2 \mathrm{D}$ structure as graphene, ${ }^{8}$ depending on the application. In appropriate environmental conditions e.g., temperature and humidity, a sensing layer can either experience a reversible change in itself, introduce a change in the composition of the gas species, or both, in a way that the change can be electrically read out. Examples of the former are oxygen adsorption on metal oxides ${ }^{9}$ and of the latter, the catalytic properties of $\mathrm{Pt}$ for $\mathrm{CO}$ oxidation utilized in $\mathrm{CO}$ sensing (see Paper 5).

This research focuses on two main topics about gas sensors:

1. Ohmic contacts to high-temperature semiconductor-based chemical gas sensors.

2. Studies of new structures and materials as sensing layers.

Sensors intended for harsh environment applications generally need to maintain their properties for roughly a few thousands of hours in order to be commercially viable. A main reason for high-temperature malfunction of semiconductor-based electronic device, in particular gas sensors, is the degradation of the ohmic contacts. Within the first research topic, I studied the growth of ohmic contacts to the widely used semiconductor for hightemperature electronics, $4 \mathrm{H}-\mathrm{SiC}$, for high-temperature applications. ${ }^{10}$ For this purpose, commonly synthesized contacts are not suitable due to the low stability at harsh working conditions. That can be basically the result of three main issues. Firstly, the presence of low-melting point elements in the ohmic contact, as Al, which melt at high temperatures $\left(>600^{\circ} \mathrm{C}\right)$. Secondly, oxidation which deteriorates the electrical conductivity through the contact, and thirdly, interdiffusion between the metallic components comprising the ohmic contacts which can affect the ohmicity. To overcome these obstacles, improving the previously reported growth methods, designing durable oxidation-barrier capping layers, and synthesizing new contact-materials are the focus.

For the second research topic, I investigated the improvement of the sensing performance of Pt-based sensing layers in field-effect gas sensors. This project started with modification of field-effect-based metal oxide semiconductor (MOS) CO sensors by the 
synthesis of monolayer iron oxide on the Pt sensing layers. Monolayer metal oxides have already been reported to enhance the catalytic properties of $\mathrm{Pt}$, which is a promising result to be fitted into improving the performance of gas sensors. In that respect, I also studied a newly synthesized group of 2D materials for sensing properties. The focus was on metal carbide nanosheets known as MXene phases. These materials possess a very high surface to volume ratio as well as active surfaces for gas adsorption and are thus promising to be studied as sensing layers. Due to several experimentally unexplored features of these newly synthesized materials, ab initio theoretical studies were used to simulate their properties.

\subsection{SiC and its status for high-temperature gas-sensor applications}

$\mathrm{SiC}$ is a (IV-IV) solid compound in which each $\mathrm{Si} / \mathrm{C}$ atom bonds to four $\mathrm{C} / \mathrm{Si}$ atoms. This compound can form different polytypes. All can be constructed by the same building block which is a tetrahedron with a silicon atom at the center and four carbon atoms at each corner (see Figure 1.1). ${ }^{11}$ Another building block can also be constructed by $180^{\circ}$ rotation of the first. The number of different polytypes of this compound is interestingly high. In 1893, the polytypism was discovered for SiC. ${ }^{12} 70$ years later about 140 different polytypes had been discovered ${ }^{13}$ and nowadays, the number is usually mentioned by an estimate above $250 .^{14}$

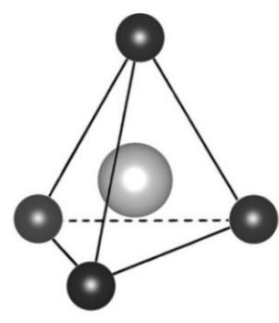

Silicon



Figure 1.1 4H-SiC crystal. (Left) Building block of all of the polytypes of SiC. (Right) 4H-SiC crystal through [1100] plane, showing the ABCB stacking sequence. 
One of the most-studied and commercially available $\mathrm{SiC}$ polytypes is $4 \mathrm{H}-\mathrm{SiC}$, the crystal structure of which is schematically illustrated in Figure 1.1. It has a hexagonal crystal structure with "ABCB" stacking sequence. This phase is a wide-band-gap semiconductor with an indirect gap of $3.26 \mathrm{eV}{ }^{11}$ This phase is known as an inert phase with stable electronic and chemical properties. ${ }^{10}$ In addition, its wide electronic band-gap provides the possibility to be used at higher temperatures than, e.g., Si or Ge, due to the negligible number of thermally generated intrinsic charge carriers. ${ }^{11}$ All these properties make this phase ideal for applications in gas sensors where stability and high-temperature semiconducting properties are of crucial importance. ${ }^{15}$ In addition, growth of an electrically insulating oxide $\left(\mathrm{SiO}_{2}\right)$ on $4 \mathrm{H}-\mathrm{SiC}$ facilitates the fabrication of field-effect metal oxide semiconductor devices (MOS) to be utilized as capacitors or in particular, capacitor-type gas sensors, (see Paper 5). One necessary component for SiC-based devices is a suitable ohmic contact. A wide range of ohmic contacts have been synthesized for this semiconductor based on e.g., $\mathrm{Ni}^{16,17}, \mathrm{Ti}^{18,19}$, or $\mathrm{Ta}^{20,21}$ However, almost all have the same drawback for high-temperature applications in air: fast degradation mainly due to oxygen diffusion and the subsequent oxidation of the ohmic contact material. ${ }^{22-24} \mathrm{With}$ this problem solved, there would be a great potential for $\mathrm{SiC}$ based sensors/electronics for performance control of combustion- or jet engines, especially when integrated into multi-sensor/driver and data acquisition systems without the need for external cooling. It would also provide spin-off effects in other areas such as for space $^{25}$ and geological explorations.

\section{2 $M_{n+1} A X_{n}$ phases and MXene}

$M_{n+1} A X_{n}$ phases ( $n=1-3$ and possibly higher) are a large group of ternary ceramics. In this notation, $\mathrm{M}$ denotes early transition metals, A represents elements from groups 12 to 16 , and $\mathrm{X}$ is $\mathrm{C}$ or $\mathrm{N} .{ }^{26,27} \mathrm{M}_{\mathrm{n}+1} A X_{n}$ phases crystalize in a hexagonal lattice with $M_{n+1} X_{n}$ sheets interleaved with A-layers, (see Fig 1.2 (a) which illustrates the crystal structure of $\mathrm{Ti}_{3} \mathrm{AlC}_{2}$ ). They possess a mixed nature of metal/ceramic properties as resistance to wear and thermal shock likewise ceramics while showing high thermal and electrical conductivities as metals. ${ }^{27}$ Regarding their properties, they appear to be promising as 
ohmic contacts which can withstand harsh working conditions. The fact which already links $\mathrm{M}_{\mathrm{n}+1} \mathrm{AX}_{\mathrm{n}}$ phases and $4 \mathrm{H}-\mathrm{SiC}$ ohmic contacts is that the chemical product of hightemperature solid-state reaction of $\mathrm{Ti}$ and $4 \mathrm{H}-\mathrm{SiC}$ performed for the synthesis of ohmic contacts is a $\mathrm{M}_{\mathrm{n}+1} \mathrm{AX}$ phase: $\mathrm{Ti}_{3} \mathrm{SiC}_{2}$. This phase forms an ohmic contact to $4 \mathrm{H}-\mathrm{SiC}$ with several growth methods reported (see Paper I).

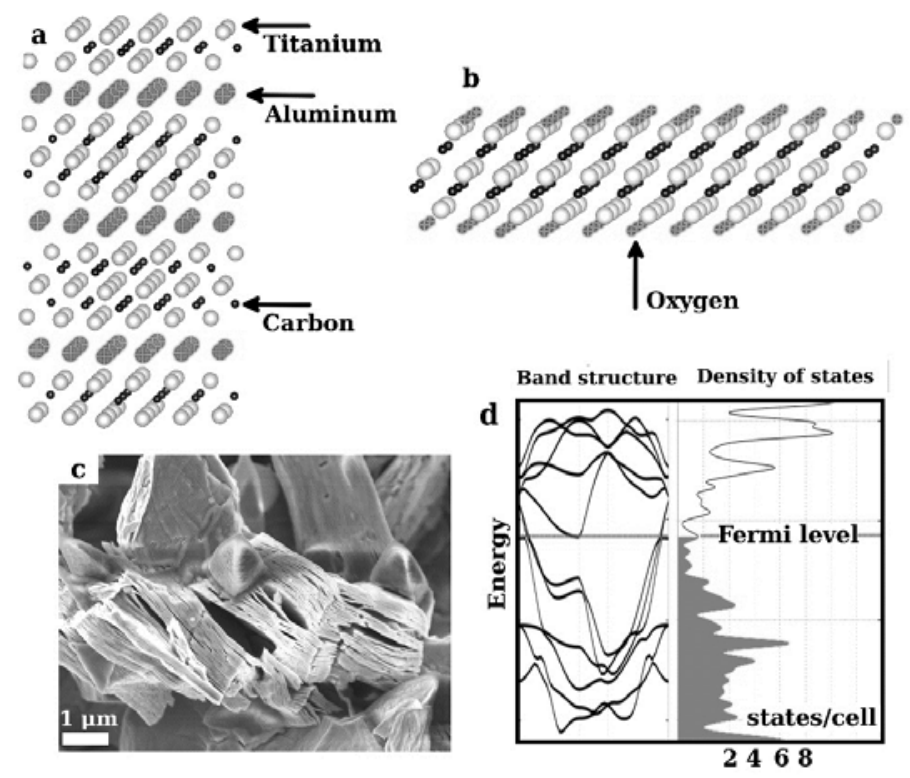

Figure 1.2 $\mathrm{M}_{\mathbf{n}+1} \mathbf{A} \mathbf{X}_{\mathbf{n}}$ phase and MXene. (a) Crystal structure of $\mathrm{Ti}_{3} \mathrm{AlC}_{2} \mathrm{MAX}$ phase. (b) The corresponding MXene phase synthesized from $\mathrm{Ti}_{3} \mathrm{AlC}_{2}$ phase. (c) Scanning electron microscopy image of $\mathrm{Ti}_{3} \mathrm{C}_{2}$-based MXene phase. (d) Electronic band structure and density of states for $\mathrm{Ti}_{3} \mathrm{C}_{2}-\mathrm{O}_{2}$ MXene phase calculated by density functional theory-based simulation.

The possibility to chemically etch away the A-layers of some $M_{n+1} A X_{n}$ phases have been experimentally reported resulting in the synthesis of $M_{n+1} X_{n}$ sheets as either isolated similar to graphene, ${ }^{28}$ nano-powder, ${ }^{29}$ clay, ${ }^{30}$ or thin films ${ }^{31}$ called MXenes. ${ }^{32,33}$ The $\mathrm{M}_{\mathrm{n}+1} \mathrm{X}_{\mathrm{n}}$ notation does not completely describe the chemical nature of MXenes since it neglects any residual material being bonded to the sites originally belonged to the Alayers. It has been reported that ${ }^{34,35}$ the $\mathrm{M}_{\mathrm{n}+1} \mathrm{X}_{\mathrm{n}}$ layers are terminated with $\mathrm{F}, \mathrm{O}$, and $\mathrm{OH}$ describing them as materials with active surfaces. Fig 1.2 (b) schematically shows a $\mathrm{Ti}_{3} \mathrm{C}_{2}$ MXene sheet fully terminated with oxygen. Figure 1.2 (c) is a scanning electron 
microscopy image of $\mathrm{Ti}_{3} \mathrm{C}_{2}$-based MXene in which the layered structure of MXene sheets can be observed.

MXenes are experimentally reported to be electronically conductive ${ }^{33}$ while theoretical results have also shown that some MXene phases can be semiconducting. ${ }^{36}$ Figure 1.2 (d) is the electronic band structure and density of electronic states for $\mathrm{Ti}_{3} \mathrm{C}_{2}-\mathrm{O}_{2}$ showing the metallic characteristic of this phase. Their high surface to volume ratio and electrical conductivity lead to the idea that MXenes may be used as gas sensing materials. Several issues can be studied within this topic, such as gas adsorption properties of MXenes and the corresponding influence on their electrical properties, stability of MXenes above room-temperature in which chemical gas sensors normally operate, and ab initio modeling of MXene properties to extend the knowledge and understanding about their properties. 


\section{Ohmic Contacts}

The term ohmic contact is named after the $19^{\text {th }}$ century German scientist Georg Ohm and describes a special case of electronic transport through heterojunctions. An ideal ohmic contact for semiconductor-metal junctions corresponds to a low resistance $\left(\leq 10^{-5} \Omega \mathrm{cm}^{2}\right)^{21}$ metal contact on a semiconductor in which the electrical current-to-voltage ratio is linear, normal to the junction. In practice, however, the definition is less strict and can be stated as a junction with linear or quasi-linear current-to-voltage ratio across the junction with a voltage drop less than the active parts of the device. ${ }^{37}$ Linear current-to-voltage ratio is equivalent to non-rectifying behavior showing no, or not significant, electrostatic barrier between the semiconductor and the metal contact. The barrier height in this case can be schematically explained using the Schottky-Mott approach stating that the barrier height equals the difference between the metal work function and the ionization energy of the semiconductor with respect to the vacuum level. ${ }^{38}$ This is due to the band bending within the semiconductor interface which can create an electrostatic barrier for the charge carriers to enter the metal (see Figure 2.1 (a) and (b) showing the band bending in a ntype semiconductor with a work function (ionization energy) lower than that of the metal). ${ }^{38}$ 
A reason for commonly inaccurate prediction of the barrier height by the abovementioned approach can be explained by John Bardeen's findings stating that the existence of electronic states at the surface of the semiconductor may act as if the Fermi level is located (pinned) at the center of the band gap, being independent of the metal work function. ${ }^{39}$ To maintain the charge neutrality of the surface due to the existence of surface states, they are assumed to be filled up to a neutral level $\varphi_{0}$, located within the forbidden gap. This phenomenon is known as Fermi level pinning and generally provides predictions closer to experimental data. In this approach, the importance is that the barrier forms inside the semiconductor and due to the screening of the bulk by the surface states, the metal contact resembles a metal-metal junction (see Figure 2.1 (c)).

a

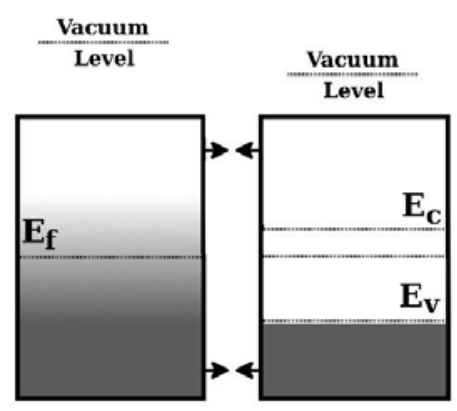

b

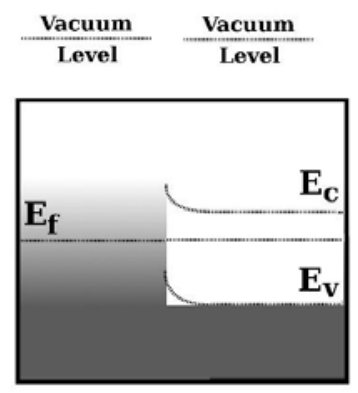

C

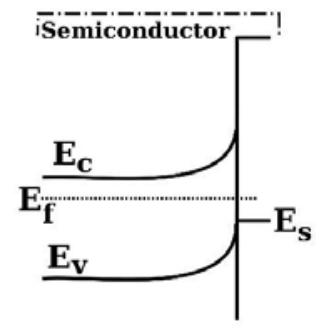

Figure 2.1 Metal junctions on semiconductors. Schematic illustration of band bending at an n-type semiconductor/metal junction, (a) before creating the contact, (b) band bending according to SchottkyMott model, and (c) Fermi level pining phenomenon.

Following Bardeen's model, Cowley and Sze suggested an equation ${ }^{40}$ for calculating the barrier height which simplified form is, ${ }^{38}$

$$
\begin{gathered}
\varphi_{b n}=\gamma\left(\varphi_{m}-\chi_{s}\right)+(1-\gamma)\left(E_{g}-\varphi_{0}\right), \\
\gamma=\frac{\epsilon_{i}}{\epsilon_{i}+e \delta D_{s}}
\end{gathered}
$$

In equation (2.1), $\varphi_{m}$ is the metal work function, $\chi_{s}$ is the electron affinity of the semiconductor, i.e., the energy difference between the vacuum level and the bottom of the conduction band, and $E_{g}$ is the semiconductor band gap. $\gamma$ is the weighting factor 
which depends on the permittivity $\epsilon_{i}$, surface state density $D_{s}$, and the thickness of the interfacial layer $\delta$. In case there is no surface state density $\left(D_{s}=0\right)$, then equation (2.1) is simply the Schottky-Mott approach. On the other hand, if the surface state density is very high, then $\gamma$ becomes very small and the barrier height has no relation to the metal properties becoming $E_{g}-\varphi_{0}$, as the Fermi level pinning phenomena states .

It should be mentioned that none of the above-mentioned models can exactly predict the barrier height, ${ }^{38}$ especially for SiC-based contacts for which usually partial Fermi level pinning is used for explanation of corresponding experimental data. ${ }^{21}$ Recent theoretical studies on this issue have been more focused on density functional theory based simulations. There, rather than the bulk properties of both the semiconductor and the metal, the very first atomic layers at the interface have shown to possess the key role in defining the transport behavior (see chapter 5 for a discussion on density functional theory (DFT)). ${ }^{41-43}$ This idea can be supported using an experimental report on this subject. It is known that $\mathrm{Ti}_{3} \mathrm{SiC}_{2}$ forms an ohmic contact to $4 \mathrm{H}-\mathrm{SiC}$ which is generally the product of a high-temperature solid-state reaction of $\mathrm{Ti}$ on $4 \mathrm{H}-\mathrm{SiC}$ (see Paper 1 for a summary and corresponding reports). However, direct synthesis of this phase on $4 \mathrm{H}-\mathrm{SiC}$ is reported to be of Schottky behavior. ${ }^{18}$ This example shows that even in case of the same semiconductor and the same metal, it is the synthesis process which defines the transport properties. Therefore, restricting the influential factors on the properties of semiconductor-metal junctions only to the factors used in Schottky-Mott or Bardeen's statements cannot construct a detailed and accurate model.

\subsection{Ohmic contacts to $4 \mathrm{H}-\mathrm{SiC}$}

The general trend for the synthesis of ohmic contacts to $4 \mathrm{H}-\mathrm{SiC}$ starts from metal deposition on a clean surface of this semiconductor, followed by an annealing step. Niand Ti-based contacts are two of the mostly used options for this purpose. At this stage, the deposited films behave as Schottky contacts. The annealing process-step leads to a solid-state reaction at the interface which transforms the interfacial region to a silicide or carbide phase for the $\mathrm{Ni}$ and $\mathrm{Ti}$ cases, respectively, resulting in a Schottky to ohmic transition in the electronic transport mechanism. The Schottky barrier drop and its 
consequent ohmic behavior is the result of the aforementioned reaction, without which an ohmic contact cannot form. In the following sections, a more detailed description about different ohmic contacts is provided.

\subsubsection{Ni-based ohmic contacts to $4 \mathrm{H}-\mathrm{SiC}$}

$\mathrm{Ni}$ has been widely used for this purpose $\mathrm{e}^{44-47}$ based on the same process method discussed above. The annealing process-step for this element results in the formation of silicide phases in the contact, which are $\mathrm{Ni}_{2} \mathrm{Si}, \mathrm{NiSi}$, or $\mathrm{Ni}_{31} \mathrm{Si}_{12}$. For this reaction to happen, it is clear that the elemental sources for $\mathrm{Ni}$ and $\mathrm{Si}$ are the deposited metal and the substrate, respectively, but since the $\mathrm{SiC}$ substrate supplies $\mathrm{Si}$ atoms, unbonded $\mathrm{C}$ atoms would also be an inevitable product. $\mathrm{C}$ atoms are reported to stay in the contact either in an amorphous or graphite phase. ${ }^{46}$ It should be mentioned that the use of other metals together with $\mathrm{Ni}$ in the contact has also been studied, e.g., Al. Due to the relatively high vapor pressure of $\mathrm{Al}$, it would evaporate during the annealing process-step and at the same time enhances the properties of the contact, like preventing void formation. ${ }^{47}$

\subsubsection{Ti-based ohmic contacts to $4 \mathrm{H}-\mathrm{SiC}$}

Another widely used element for the synthesis of ohmic contacts to $4 \mathrm{H}-\mathrm{SiC}$ is $\mathrm{Ti}$ using the same deposition-annealing approach discussed above. ${ }^{48-51}$ Similar to the case of $\mathrm{Ni}$, Al has also been deposited together with Ti during the deposition process as Ti/Al multilayers. The final products of the annealing process-step are mainly $\mathrm{Ti}_{3} \mathrm{SiC}_{2}$ and $\mathrm{Ti}_{3} \mathrm{Al}$. However; it is the $\mathrm{Ti}_{3} \mathrm{SiC}_{2}$ phase which grows at the interface and is thus believed to be the reason for ohmic properties. ${ }^{52-54}$ There have been several suggestions for the mechanism of the Schottky-ohmic transition, such as Al diffusion inside $\mathrm{SiC}$ which results in an extra doping level at the surface, ${ }^{55}$ or formation of spikes and pores made by the annealing process-step which can enhance the charge transport. ${ }^{56}$ The former reason has been ruled out since no $\mathrm{Al}$ segregation has been reported at the interface, while the latter has been ruled out by electron microscopy studies showing a smooth interface with no sign of major defects. ${ }^{41,54}$ Based on that, the only reason remained for explaining 
the ohmic properties is the formation of $\mathrm{Ti}_{3} \mathrm{SiC}_{2}$ at the contact area which is also supported by DFT-based simulations. ${ }^{41-43}$ Nontheless, formation of $\mathrm{Ti}_{3} \mathrm{SiC}_{2}$ is not sufficient. Direct growth of this phase on $4 \mathrm{H}-\mathrm{SiC}$ has been reported by sputtering through three elemental targets, ${ }^{57}$ but the same annealing process-step was required to obtain an ohmic contact. ${ }^{18}$ This implies considering atomic-scale properties of the interface for any explanation for ohmic properties, as discussed in section 2.1.

Aside from the influential factors on ohmic properties of Ti-based contacts on $\mathrm{SiC}$, the question remains about the role of $\mathrm{Al}$ in the high-temperature solid-state reaction which happens during the annealing process-step. Al is said to be responsible to form a liquid alloy which can lead into the solid-state reaction and formation of $\mathrm{Ti}_{3} \mathrm{SiC}_{2} .{ }^{52} \mathrm{In}$ paper 1 , we showed that even in the absence of this element, the reaction takes place which rules out any need for any catalytic property of $\mathrm{Al}$ for the growth of $\mathrm{Ti}_{3} \mathrm{SiC}_{2}$ on $4 \mathrm{H}-\mathrm{SiC}$ (see Paper 1). However, given the fact that the annealing process-step is performed for predeposited films, Al can be responsible for providing sufficient mobility to the atoms to form the rather large cell of $\mathrm{Ti}_{3} \mathrm{SiC}_{2}$ followed by its evaporation from the film. 


\section{Thin Film Synthesis and Characterization}

\subsection{Synthesis}

The term thin film refers to a solid layer on a support, (or substrate), with a thickness ranging generally from few atomic layers ${ }^{58}$ to less than a micrometer. Thin films have a very long history dating back to 5000 years ago when Egyptians were able to process few-hundred-nanometer thick decorative gold coatings. ${ }^{59}$ However, advanced scientific investigation of thin films properties and applications can hardly be considered before the era of modern physics ${ }^{60}$ being about a century old. Nowadays, applications of thin films are pervasive in science, technology, and also everyday life ranging from solar cells ${ }^{61}$ to antibacterial surfaces ${ }^{62}$ or from decorative coatings ${ }^{63}$ to hard coatings on industrial inserts. ${ }^{64}$ Depending on the functionality and the desired properties of the films, different growth techniques are available. A major branch of thin film deposition techniques is vapor deposition, so named because the materials to be deposited are in the vapor phase before reaching to the substrate. Depending on the means of providing the vaporized materials, the deposition methods can be classified into two different groups: chemical vapor deposition (CVD) and physical vapor deposition (PVD). 


\section{CVD}

In this technique, the material to be deposited on the substrate is the product of a chemical reaction in the gaseous state. A related example to this thesis is CVD growth of $\mathrm{SiC}^{65}$ The growth mechanism in CVD operates close to thermodynamic equilibrium, in contrast to PVD which is a far-from-equilibrium technique. Since the deposition source in this technique is gaseous, it provides a possibility to grow films on any object with any shape which are just placed in the deposition chamber, e.g., cutting tools. Figure 3.1 schematically shows a chamber for CVD growth of hard coatings on industrial inserts.

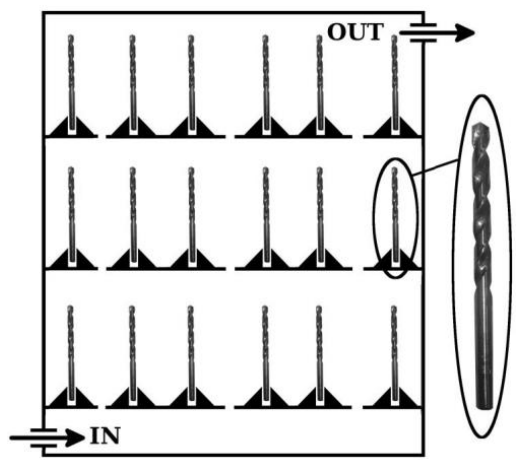

Figure 3.1. CVD chamber. Coating of metal tools, positioning the substrates (tools), and inlet/outlet of the materials to be deposited.

\section{PVD}

In PVD, the material to be deposited is vaporized from a solid or liquid source by, e.g., thermal evaporation or plasma-, arc-, or laser-induced sublimation. The first requirement for this method is sufficient vacuum-level in the deposition chamber. Vacuum generally serves to exclude any chemical reaction of the vaporized material with the atmosphere, to maintain the momentum of the vaporized material towards the substrate, and to eliminate trapped species inside the film or at the substrate surface. Depending on the vacuum level, the vaporized particles have comparable mean-free-path length with targetsubstrate distance and do not experience any collision that can change their direction, thus, they travel in straight lines. Therefore, film growth by this method is generally confined to the line-of-sight of the deposition source. However, ionizing the vaporized 
species puts forward the possibility to change their direction by applying electric fields via the substrates and to modify the deposition areas and directions. ${ }^{66}$

\section{Sputtering}

Sputtering is a widely-used PVD technique for scientific and industrial purposes. In this method, atoms of the target material which are to be deposited on the substrate are induced to sublime by the means of momentum exchange with surrounding ionized atoms which are in plasma state. Ar is commonly used for creating the plasma; however, it is not the only possible choice. For depositing oxide or nitride films from elemental targets, $\mathrm{O}_{2}$ or $\mathrm{N}_{2}$ is introduced to the chamber, respectively, along with the main sputtering gas, ${ }^{67}$ or in some cases, sputtering can be done by only the reactive gas like $\mathrm{N}_{2}{ }^{68}$ There are different types of sputtering, e.g. DC diode, RF-diode, ion beam diode, or magnetron diode, ${ }^{66}$ the latter being widely used nowadays. Magnetrons are the main components to create and maintain the plasma, transfer momentum to the ionized species by an electrical potential difference, and control the flow of target atoms towards the substrate while holding the targets.



Figure 3.2. Magnetron. Schematic illustration of a magnetron surface and corresponding atomic kinetic interactions.

The deposition rate for sputtering is generally lower than thermal evaporation (see the next section for the latter). ${ }^{69}$ On the other hand, the kinetic energy of the vaporized atoms is considerably higher for sputtering. ${ }^{69,70}$ Figure 3.2 shows a schematic illustration of the main components of a magnetron. Magnets produce a magnetic field approximately parallel to the target. This configuration forces the electrons to move in a helix-like path 
parallel to the target above its surface leading to the creation of the plasma with high density and thus, a suitable deposition rate can be achieved.

\section{Thermal evaporation}

In this PVD method, the material to be deposited is evaporated using high temperature achieved by resistive heating. The resistive filament or boat is generally made of graphite, Ta, W, or Mo which can withstand high temperature ${ }^{69}$ with negligible vapor pressure compared to the material they are holding. For the materials which require higher temperature to provide a sufficient vapor pressure, electron beam evaporation is used instead. For this purpose, a beam of electrons generates the required heat for deposition. Compared to sputtering, poorer film uniformity and density is generally achieved by thermal evaporation since there is less control on the amount and uniformity of the vaporized material as well as the momentum of the vaporized species.

This method is commonly used for deposition of elemental electrical contacts which is also used in our study to deposit backside Ni-based electrical contacts to a SiC field effect CO sensor, (see Paper 5).

\subsection{Characterization}

\subsubsection{X-ray diffraction (XRD) analysis}

Diffraction of x-rays by crystals is one of the most influential discoveries in science. Xrays were first discovered by the first Nobel Prize winner in physics, Conrad Wilhelm Röntgen in 1895. X-ray diffraction by crystals was then discovered by Max von Laue in 1914, for which he won the $14^{\text {th }}$ Nobel Prize. Finally, the $15^{\text {th }}$ Nobel Prize in 1915 was awarded to William Henry Bragg and William Lawrence Bragg for formulating the model for x-ray diffraction by crystals. Since then, x-ray diffraction analysis has been acting as the eye for materials scientists to observe the atomic orders in crystals, based on Bragg's law. In a crystal with $d$ as the spacing between the planes parallel to the surface, constructive diffraction for an electromagnetic wave with incident angle $\theta$ and wavelength $\lambda$ can occur only if the Bragg condition below is fulfilled. 


$$
2 d \sin (\theta)=n \lambda
$$

Thus, assuming $d$ to be of the size of the lattice spacing in crystals $\left(\approx 10^{-10} \mathrm{~m}\right), \lambda$ should also be within the same order of magnitude, which corresponds to x-rays. Bragg's law is the necessary condition for constructive diffraction. However, it is not sufficient, since it does not account for the distribution of the atoms inside the lattice unit cell which in turn can cause destructive interference. This is considered by the structure factor which is defined by the equation below.

$$
\begin{gathered}
F_{h k l}=\sum_{n=1}^{N} f_{n} e^{2 \pi i\left(h u_{n}+k v_{n}+l w_{n}\right)}, \\
I \sim\left|F_{h k l}\right|^{2}
\end{gathered}
$$

In equation (3.2), $f$ is the atomic scattering factor, $(h k l)$ defines the lattice planes, and $(u, v, w)$ defines $N$ atomic positions inside the unit cell. The diffraction intensity, $I$, is then proportional to the square magnitude of the structure factor, (see equation (3.3)). As an example, for a simple cubic lattice with $\mathrm{N}=1$ and $(\mathrm{u}, \mathrm{w}, \mathrm{v})=(0,0,0)$, the structure factor is independent of (hkl) planes. On the other hand, for a bcc lattice with $\mathrm{N}=2$ and $(\mathrm{u}, \mathrm{w}, \mathrm{v})=$ $(0,0,0)$ and $(1 / 2,1 / 2,1 / 2)$, the structure factor equals zero for $(\mathrm{h}+\mathrm{k}+\mathrm{l})=$ odd and thus, no diffraction can occur for such $(\mathrm{h}, \mathrm{k}, \mathrm{l})$ combinations.

A standard configuration for XRD analysis is called $\theta-2 \theta$ scan where $\theta$ and $2 \theta$ are the angles between the X-ray beam and the sample and detector, respectively. That configuration resembles that of a regular mirror (see Figure 3.1(left)). Peak positions in this configuration correspond to lattice dimensions while their intensity and broadening is related to the phase content/strain and crystallite size, respectively.

Figure 3.1(b) is an example showing two diffractograms related to two sputter-deposited films. The deposition processes were exactly the same for the two films (Ti, Al, and C targets at $900{ }^{\circ} \mathrm{C}$ substrate temperature), however, different substrates were used being $\mathrm{Al}_{2} \mathrm{O}_{3}$ and $4 \mathrm{H}-\mathrm{SiC}$. According to the crystal structure and surface orientation of these two substrates, both were suitable candidates for the growth of $\mathrm{Ti}_{2} \mathrm{AlC}$, but it was only on the $\mathrm{Al}_{2} \mathrm{O}_{3}$ substrate that this phase could grow. This comparison between the diffractograms 
was the motivation for the experiments I performed to study any surface reaction between sputter deposited atoms, $(\mathrm{Ti}, \mathrm{Al}$, or $\mathrm{C})$ on $4 \mathrm{H}-\mathrm{SiC}$ which prevented the growth of $\mathrm{Ti}_{2} \mathrm{AlC}$ on $4 \mathrm{H}-\mathrm{SiC}$. Those experiments are reported in Paper 1. I found that the reaction between $\mathrm{Ti}$ and $4 \mathrm{H}-\mathrm{SiC}$ resulted in the dissociation of bondings between $\mathrm{Si}$ and $\mathrm{C}$ atoms which in turn destroyed the appropriate elemental content being deposited on the substrate needed for the growth of $\mathrm{Ti}_{2} \mathrm{AlC}$.
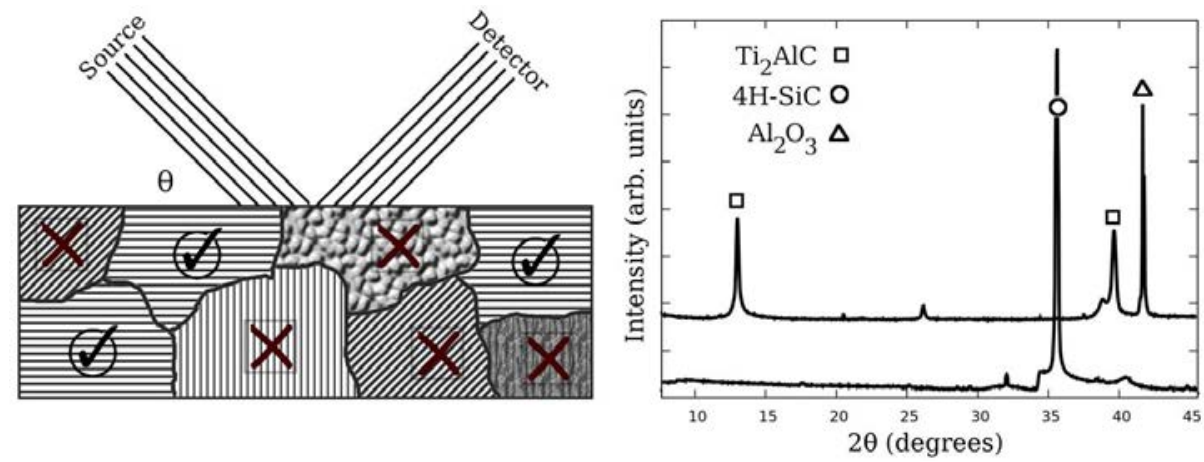

Figure 3.1 X-ray diffraction. (Left) Schematic illustration of different grains with different orientations and crystallographic structures and their contributions to the diffracted beam. (Right) Diffractograms related to $\mathrm{Ti}, \mathrm{C}$, and $\mathrm{Al}$ co-sputtered in the same deposition conditions but on different substrates.

\subsubsection{Electron microscopy}

Nowadays, micro- and sub-micro-scale experimental materials science is coupled with electron microscopy, which refers to exploiting accelerated electrons as the illumination source of a microscope. The wave nature of electrons has been used for this purpose and has resulted in the invention of the transmission electron microscope (TEM) in 1931. Based on de Broglie's hypothesis, the wavelength of electrons with the classical energy term at $200 \mathrm{kV}$ of accelerating voltage is about $2.7 \times 10^{-3} \mathrm{~nm}$. This wavelength is shorter than that of visible light by about five orders of magnitude making it possible to obtain higher resolutions by an electron microscope compared with ordinary optical microscopes. The particle nature of accelerated electrons and their interaction with matter is another aspect of electron microscopy. An incident beam of electrons on a surface gives rise to different phenomena, e.g., electron repulsion from the surface or electromagnetic 
radiation; the investigation of which is the base for the scanning electron microscope (SEM). Through the following sections TEM and SEM, which are used in this study are described.

\section{TEM}

This technique schematically resembles ordinary optical microscopy, although for TEM, electrons and electromagnetic lenses are used instead of the visible light and conventional optical lenses, respectively. In theory, the wavelength of accelerated electrons in a 200$\mathrm{kV}$ TEM is small enough for any desired magnification in materials science, even for the size of a hydrogen atom. In practice however, the aberration of electromagnetic lenses are yet far from ideal, keeping the resolution of the state-of-the-art instruments around $5 \times 10^{-2} \mathrm{~nm} .^{71}$
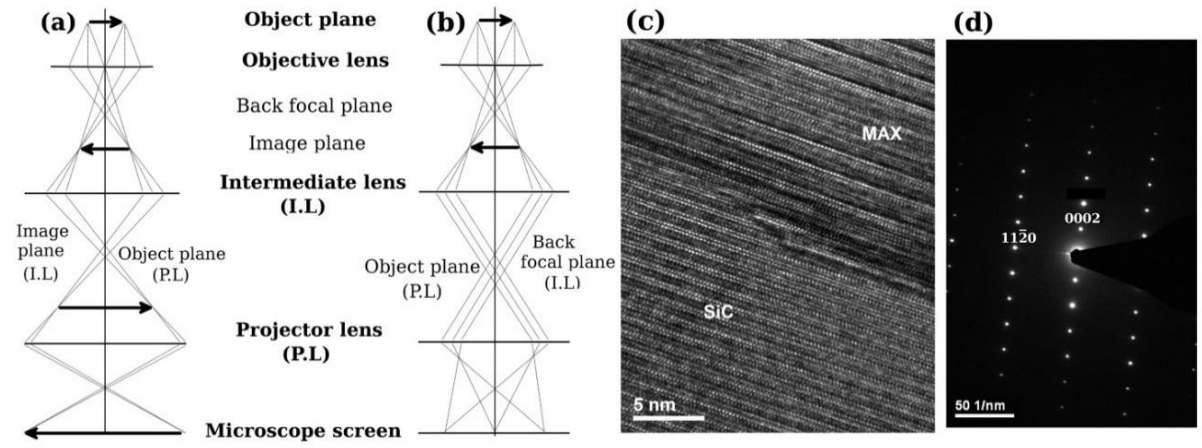

Figure 3.2 Transmission electron microscopy. (a) and (b) Electron optical-path in a TEM for visualizing the diffraction pattern and imaging, respectively. (c) HRTEM image of $\mathrm{Ti}_{3} \mathrm{SiC}_{2}$ (MAX) grown on $4 \mathrm{H}-\mathrm{SiC}$. (d) Diffraction pattern of $\mathrm{Ti}_{5} \mathrm{Si}_{3} \mathrm{C}_{\mathrm{x}}$ grown as a side product of $\mathrm{Ti}_{3} \mathrm{SiC}_{2}$.

Figure 3.2 (a) illustrates the electron optical-path for imaging in a TEM, showing multiple magnifications of the sample by a series of electromagnetic lenses. Diffraction also occurs for the electron waves being scattered by the periodic lattice. Diffraction patterns in a TEM are used for phase determination of lattices inside the sample, their alignment, or describing defects. The electron optical-path for this purpose is shown in Figure 3.2 (b). 
By setting the object plane of the projector lens onto the back focal plane of the intermediate lens, a diffraction pattern forms on the screen. Generally, depending on the crystallinity of the materials, coarse-grained crystalline, nanocrystalline, or fully amorphous, the diffraction pattern ranges from a dotted pattern, concentric circles over to a broad faint halo, respectively.

In case the diffraction pattern of a particular area of the magnified image is of interest, an aperture of appropriate size is inserted in the image plane of the objective lens. This aperture selects a particular area through which the diffraction pattern is created. This is called selected area electron diffraction (SAED). Figure 3.2 (c) shows a high-resolution TEM (HRTEM), image of $\mathrm{Ti}_{3} \mathrm{SiC}_{2}$ MAX phase grown on $4 \mathrm{H}-\mathrm{SiC}$. The corresponding growth mechanism and sample properties are discussed in Paper 1. The image shows the orientation of atomic planes of the film and the substrate with respect to each other. Figure 3.2 (d) shows the diffraction pattern of $\mathrm{Ti}_{5} \mathrm{Si}_{3} \mathrm{C}_{\mathrm{x}}$ grown on $4 \mathrm{H}-\mathrm{SiC}$, which confirmed other results obtained by XRD and SEM for this phase (see Paper 1).

Scanning transmission electron microscopy (STEM) is a type of TEM in which the electron beam is focused in a narrow spot on the sample and sweeps all over the sample. This is different to the conventional TEMs in which a broad and parallel beam passes the sample. The transmitted and scattered electrons are then analyzed simultaneously using different detectors in a sufficient angle. The illumination form makes STEM a Z-contrast technique allowing for both imaging as well as providing information about the chemical nature of the specimen. Figure 3.3 (left) shows a STEM image of $\mathrm{Ti}_{3} \mathrm{SiC}_{2}$ grown on $4 \mathrm{H}-\mathrm{SiC}$. In that image, the zig-zag layers of $\mathrm{Ti}_{3} \mathrm{C}_{2}$ can be seen separated by monolayers of $\mathrm{Si}$, although, the small $\mathrm{C}$ atoms are not visible. The Ti atoms appear much brighter than Si atoms as a result of the Z-contrast quality of STEM images. Figure 3.3 (right), illustrates another STEM image from the same sample and the same location but, after exchange-intercalation of $\mathrm{Ti}_{3} \mathrm{SiC}_{2}$ with $\mathrm{Au}$. As can be seen, the zig-zag layers of $\mathrm{Ti}_{3} \mathrm{C}_{2}$ are present. However, in between the $\mathrm{Ti}_{3} \mathrm{C}_{2}$ layers, double-layers of a heavier atom than Ti resides. The double layers are composed of $\mathrm{Au}$ atoms as a result of an exchangeintercalation process with $\mathrm{Si}$. 

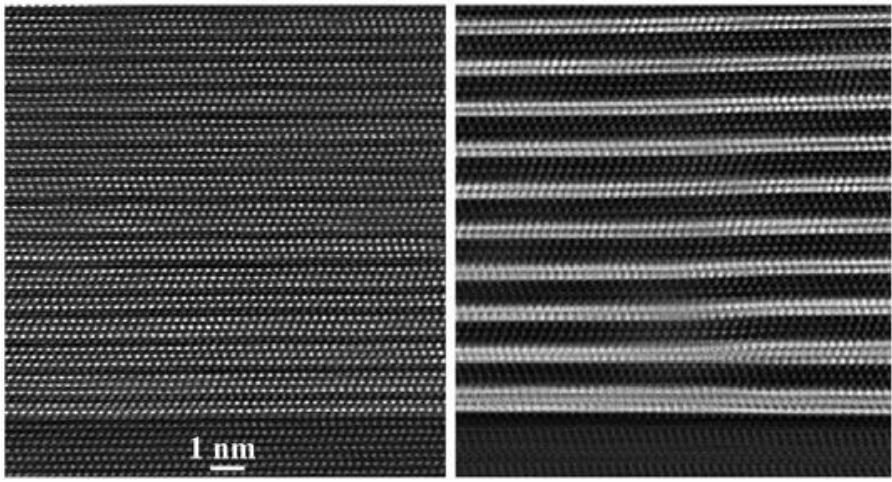

Figure 3.3. $\mathrm{STEM}$ imaging of $\mathrm{Ti}_{3} \mathrm{SiC}_{2}$ (left) and $\mathrm{Ti}_{3} \mathrm{Au}_{2} \mathrm{C}_{2}$ (right).

\section{SEM}

SEM is based on detecting the products of the interactions between an electron beam and materials surfaces. This method of topographical microscopy provides resolutions down to a few nm with a depth-of-field much larger than that of optical microscopes. ${ }^{72}$ The accelerating voltage for the electrons can be set to values ranging from a few hundred volts to around $30 \mathrm{kV}$, depending on the experimental requirements. The higher e-beam energy results in a deeper interaction volume. This technique requires the sample to be electrically conductive; otherwise the e-beam results in overcharging of the sample surface which consequently shields the sample for microscopy.

Figure 3.4 (a) schematically illustrates some possible interactions that can happen on the sample surface while Figure 3.4 (b) illustrates them with respect to the atomic energy levels $(\mathrm{K}, \mathrm{L}, \mathrm{M})$. Heat generation is the first obvious consequence of this interaction, which is a result of the momentum exchange between the e-beam and the surface as well as the induced electrical current flow. Secondary electrons (S-e), the most commonly used signal for generating images in SEM, are direct products of the impact of a highenergy external electron with an electron in atomic orbitals (see Figure 3.4 (b)). As can be seen in Figure 3.4 (a), the source for secondary electrons is near the surface where they have the possibility to escape from the bulk. Auger electrons (A-e), is a term referring to electron ejection from atomic orbitals as a result of the energy released from electron- 
hole pairing at the core levels of the same atom. Cathodoluminescence refers to electromagnetic waves generated by electron-hole pairing in an atom which may have a wavelength in the visible range. Characteristic X-rays $(\mathrm{C}-\mathrm{x})$, are generated by electronhole pairing at the core levels, which are named depending on the initial and final energy level of the electron (see Figure 3.4 (b)). Energies of characteristic X-rays act as fingerprints for different chemical elements, the probing of which is used for determining the elemental composition of a sample. This is the basis for energy dispersive $\mathrm{x}$-ray analysis (EDX). And finally, backscattered electrons (B-e) are those being reflected by the nuclei (see Figure 3.4 (b)). This phenomenon generally occurs at deeper levels in the sample where the possibility to generate backscattered electrons is considerably higher than the very first atomic layers at the surface (see Figure 3.4 (a)). SEM generally requires no sample preparation for inorganic species as long as the sample is electrically conductive and properly connected to the sample platform of the instrument.

For imaging, SEM scans the sample surface in pixels along $\mathrm{X}$ and $\mathrm{Y}$ coordinates parallel to the sample surface while the detectors, most commonly for secondary electrons or EDX, store the signal for each pixel. Finally, the whole image is generated by combining the information stored in each pixel. The depth-of-field in SEM is quite large. Thus, this technique provides 3D images of the parts of the samples being exposed to the e-beam. Figure 3.4 (c) is an SEM image of a Ti thin-film deposited on oxidized Si showing the Ti grains.
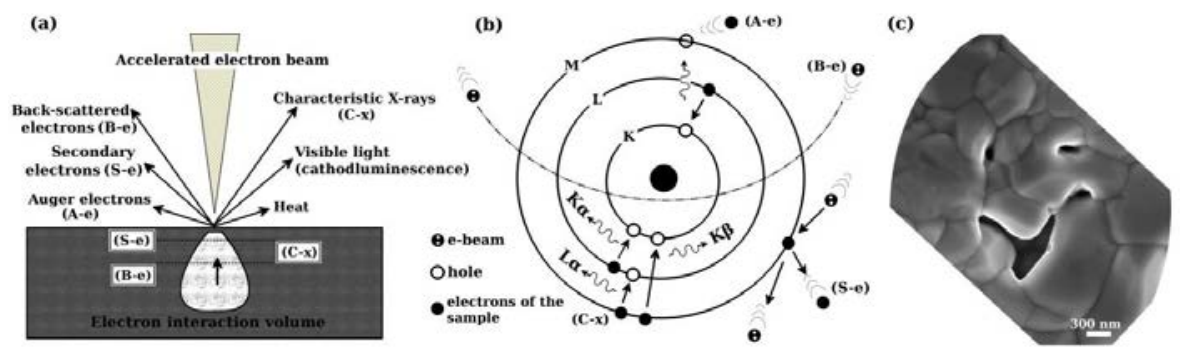

Figure 3.4 Scanning electron microscopy. (a) Different phenomena happen at the surface due to accelerated electrons/material interaction. Within the sample the electron interaction volume and the depth of occurrence for different interactions is illustrated. (b) Atomic energy levels, K, L, and M and different interactions with accelerated electrons. (c) SEM image of Ti film deposited on oxidized Si substrate. 


\subsubsection{Electrical transport measurements}

\section{Current voltage measurement for ohmic contacts}

Electric current to voltage ratio (I/V) measurements are used for studying the electrical properties of semiconductor-metal contacts. This approach is necessary to determine the linear/non-linear shape of ohmic/non-ohmic contacts and is used in this study for investigating the electric properties of the contacts discussed in Papers 1 and 2.

In a method which is also used in this study, the contact material is deposited on two separated areas on the substrate as shown in Figure 3.5 (left). Using two removable probes attached to the two individual contact areas, I/V measurement can be performed. For that reason, two removable gold-coated contacts connected to a computer-controlled sourcemeter were used, see Figure 3.5 (left)
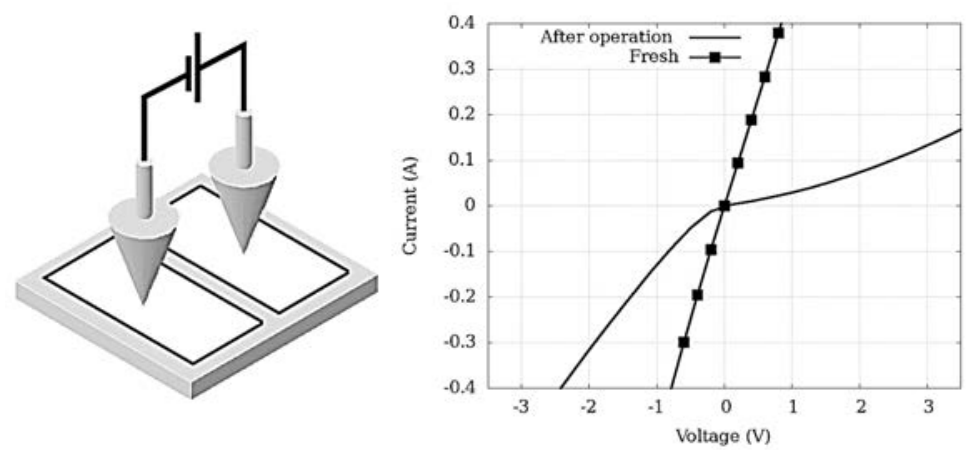

Figure 3.5 Current/voltage measurements. (Left) Schematic illustration of the experimental setup used for I/V measurement, showing two electrodes on two separated areas of the synthesized film on a substrate. (Right) I/V plot for two $\mathrm{Ti}_{3} \mathrm{SiC}_{2}$ contacts on $4 \mathrm{H}-\mathrm{SiC}$ with $250 \mathrm{~nm}$ thick iridium capping layer. One is fresh and shows ohmic property while the other has been run at $600{ }^{\circ} \mathrm{C}$ for 100 hours and shows Schottky property due to degradation.

Figure 3.5 (right) shows the corresponding result for two samples that both are $\mathrm{Ti}_{3} \mathrm{SiC}_{2}$ contacts on $4 \mathrm{H}-\mathrm{SiC}$ with $250 \mathrm{~nm}$ thick Ir oxygen-barrier capping layer. One plot belongs to a fresh sample while the other corresponds to a sample which was aged at $600{ }^{\circ} \mathrm{C}$ air for 100 hours. As can be seen, the fresh sample shows ohmic behavior while the other resembles the properties of a leaky Schottky contact due to degradation. 


\section{Linear four-point probe}

Sheet resistance and bulk resistivity can be measured using a linear four-point probe setup as schematically illustrated in Figure 3.6 (left).$^{73}$ The setup is composed of 4 identical probes placed in-line on the sample with equal distances (s). Electrical current is passed from the two outer probes while the electrical potential drop is measured simultaneously by the two inner ones. In case of measuring on a relatively thin film, (i.e., film thickness $\ll s$ ), grown on an insulator substrate, the sheet resistance is then determined by the equation,

$$
\rho(\Omega / \mathbf{a})=\frac{\pi}{\ln (2)} \frac{V}{I}
$$

In the equation above, the dimension of the resistance is ohm/square showing the resistance of the material across any square area regardless of the square size. In order to obtain the bulk resistivity, one needs to include the thickness of the film in equation (3-4). Using the equation below, the resistivity can be determined.

$$
\rho(\Omega-c m)=\frac{\pi}{\ln (2)} t \frac{V}{I}
$$
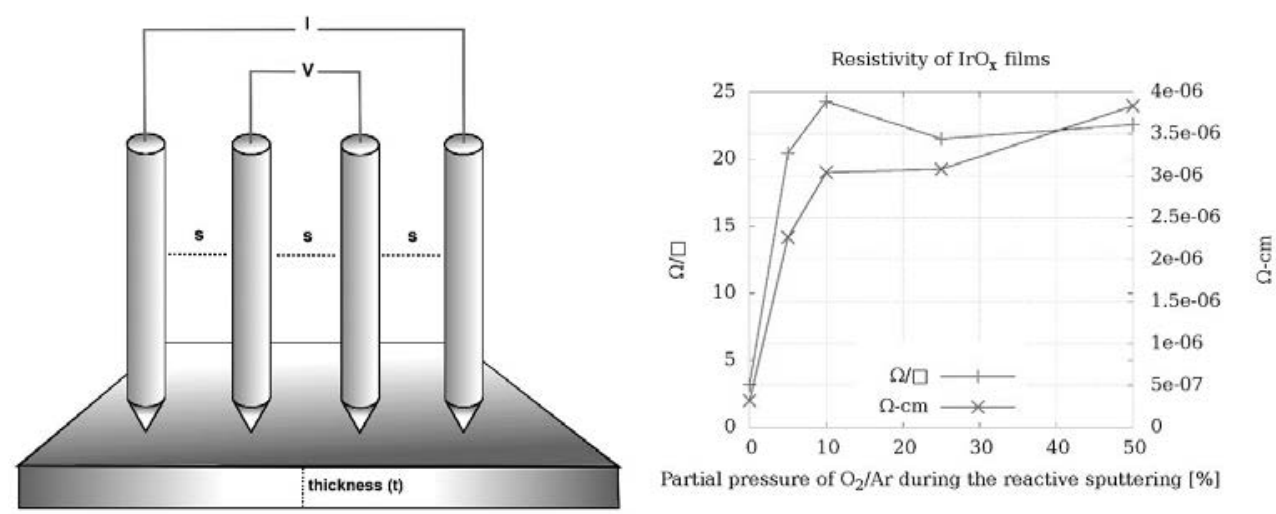

Figure 3.6. Linear four-point probe. (left) setup for 4-point probe measurement of resistivity showing 4 identical probes placed in-line at the distances of (s) on the sample with the thickness of (t), (Right) resistivity values of $\mathrm{IrO}_{\mathrm{x}}$ films deposited with different $\mathrm{O}_{2}$ content of the sputtering gas. 
Figure 3.6 (right) shows the resistivity plot of five different $\mathrm{IrO}_{\mathrm{x}}$ films deposited on identical $\mathrm{MgO}$ substrates through a reactive sputtering process with $\mathrm{O}_{2}+\mathrm{Ar}$ as the sputtering gas. Five different $\mathrm{O}_{2} / \mathrm{Ar}$ pressure ratios were used for different samples as mentioned in the figure. The sheet-resistance values of the films in ohm/square, show an increase at $10 \% \mathrm{O}_{2} / \mathrm{Ar}$, however, since the film thicknesses are not identical for different samples, this value delivers an imprecise information. By considering the film thicknesses, the plot shows the resistivity of the sputter-deposited films increases by increasing the oxygen content of the sputtering gas. 


\section{Intercalation}

\subsection{Definitions and Mechanisms}

The word intercalation is formed from two Latin words: inter (between) and calare (proclaim). The first use of this word was most probably for referring to the insertion of a day or month into the Roman calendar in order to more precisely fit it to the lunar year. ${ }^{74}$ During the past century and within the scientific community, intercalation has acquired a different meaning: insertion of one material into another. ${ }^{75}$ This new meaning, however, has a parallel to the old meaning in that the insertion mechanism does not destroy the original parts of the host material, just as the original days of the calendar remained intact by intercalation of a new day. In addition, just as an intercalated day inside the calendar could possibly be pulled out, the scientific definition of intercalation also requires this mechanism to be reversible.

Intercalation of materials can generally be sustained through two structural mechanisms within the host material: ${ }^{76}$ 
(a) Occupation of a vacant site in the host by the guest.

(b) Replacement of an already occupied site in the host by the guest, a mechanism referred to as exchange-intercalation.

Typical host materials are layered van der Waals (vdW) solids which are composed of two-dimensional stiff layers bonded together with weak vdW interactions. This provides laminar voids in between the layers (vdW gap) in which the guest species can be accommodated. A widely used layered vdW host is graphite which is the base for graphite intercalation compounds (GIC) such as $\mathrm{KC}_{8}$ or $\mathrm{CaC}_{6}$. Transition metal dichalcogenides (TMDC) are another such group of host materials with the chemical formulae of $\mathrm{MX}_{2}$, in which $\mathrm{M}$ is a transition metal atom (Mo, W, etc.) and $\mathrm{X}$ is a chalcogen atom $(\mathrm{S}, \mathrm{Se}$, or Te.). About 30 different elements have been reported to be intercalated in TMDCs, ranging from small atoms as $\mathrm{Li}$ to large ones as $\mathrm{Tl}$ or $\mathrm{Pb}{ }^{75,77}$

Intercalation is commonly a reducing-oxidation (redox) reaction. This has been formulated through the "ionic model" which is based on the estimation of the change of entropy $(\Delta G)$ during the intercalation process. ${ }^{78}$ As an example, consider the intercalation of $\mathrm{Li}$ in graphite. Figure 4.1 shows the schematic energy path for all the assumed mechanisms based on the ionic model giving rise to the intercalation. The negative value for $\Delta \mathrm{G}$, as in this image, corresponds to the possibility of the intercalation to proceed. The ionic model however is not completely capable of explaining all the experimental outcomes, e.g., zerovalent intercalants. ${ }^{79}$

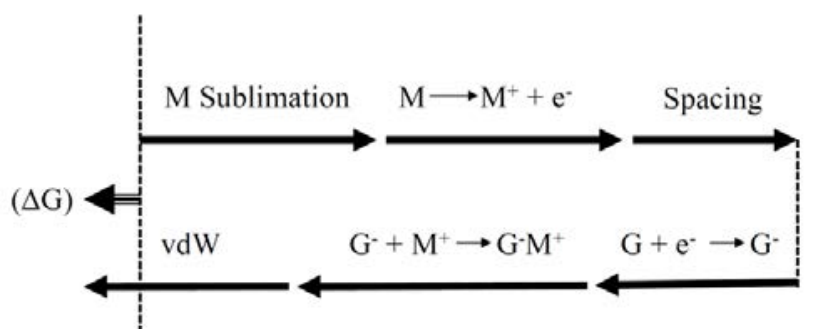

Figure. 4.1. Schematic illustration of the energy path for a metal (M) intercalation into graphite (G).

Regardless of any contradictions between the experiments and the ionic model, for an intercalation to happen, the chemical potential difference for the guest and the host before 
and after the intercalation should be negative. ${ }^{78}$ This can be utilized for ab initio theoretical prediction of the possibility of intercalation at room temperature. ${ }^{80}$ Using $a b$ initio techniques such as density functional theory, one can calculate the $0 \mathrm{~K}$ total energies of the intercalation compound and its corresponding original host and guest, without any initial assumptions about the bonding nature as in the ionic model, while considering the fact that vibrational and configurational entropy contributions to the energy at room temperature are expected to be negligible. ${ }^{81}$ An energetically favorable intercalation can then be predicted only if the value of the formula below takes negative values.

$$
\Delta E=\lceil E(\text { Intercalated Phase })-E(\text { host })-\mu(\text { guest })\rceil
$$

In formula (4.1), E corresponds to the total energy and $\mu$ is the chemical potential of the guest species. In the case of $\mathrm{Li}$ as the guest material, simulation of the metallic Li phase is considered as the standard approximation. ${ }^{81}$ In case the intercalation proceeds within a Li-electrochemical-cell, the open-circuit cell voltage can also be approximated using formula (4.1) divided by" $x \times e$ "where $x$ is the number of intercalants and $e$ is the charge of an electron. ${ }^{80}$ Experimentally, intercalation compounds can generally be synthesized through a thermal or electrochemical reaction. The mechanism can then be controlled by either temperature and/or voltage in an electrochemical cell with the host as the anode and/or the cathode. In the following section, some common experimental techniques for the synthesis and use of GICs are briefly discussed.

\subsection{Thermal Synthesis of GICs}

Intercalation into graphite can be done from vapor, liquid, or solid phase of the guest. The standard technique for intercalation from the vapor phase is the so-called two-bulb reactor. ${ }^{76,78}$ In this technique which is schematically illustrated in Figure (4.2), the host and the guest are stored in isolated areas while being internally connected through a tube. In such a reactor, they can be kept at different temperatures marked with $T_{h}$ and $T_{g}$ in the figure. Through sublimation (or evaporation) of the guest, its vaporized species reach the host and intercalates into the vdW gap. This technique provides the system of (host + guest) with the energy to extract particles from the solid phase of the guest (or liquid for 
the case of, e.g., $\mathrm{Hg}$ ) as well as that for the host to accommodate the gust particles inside its vdW gap. Through this technique, high quality ICs can be synthesized.



Figure. 4.2. Schematic illustration of two-bulb reactor for the synthesis of intercalation compounds. $T_{g}$ and $\mathrm{T}_{h}$ shows the temperatures of the guest and the host, respectively.

Intercalation from liquid or solid phase of the guest have also been reported. For the former, the procedure is immersion of the host in the liquid guest while for the latter, the procedure is carried out through compression of a mixture of powdered host and guest. ${ }^{78}$

\subsection{Applications}

Nowadays intercalation phenomena have important aspects than merely a technique for the synthesis of new structures/phases and their corresponding properties. Intercalation is the base for the development of electrical energy storage devices, e.g., Li-ion batteries. ${ }^{82}$ Taking into account the global warming caused by the use of fossil fuels, limited life-time of the fossil fuel resources, and the growing need for portable energy sources show the need for scientific investigations on different intercalation techniques as well as their reallife implementations.

Li-ion batteries store electricity by simply passing Li ions in between two different host materials acting as the cathode and the anode. In that case, the battery charges when Li intercalates into the anode and it decharges when lithium leaves the anode and intercalates into the cathode. This mechanism recquires the intercalation to be reversible in order to maintain rechargability. The anode and the cathode are separated by an electrolyte which can be either liquid, solid, or gel-type. The common features of the electrolyte are good Li-conductivity as well as high thermal and chemical stability. In order to avoide shortcircuit inside the battery, a separator is also placed inside the electrolyte which acts as a 
conductor and insulator for the Li ions and electrons, respectively. The cathode material is chosen so that its redox potential is higher than the anode. During the discharge process, the electrons move from the anode to the cathode. In energy terms, they move towards the lower energy in the cathode. Concurrently, the Li ions are released from the anode and intercalate inside the cathode. The reverse action, charging, is then carried out using an external energy source to pull the electrons from the cathode and lead them towards the anode. In such a case, $\mathrm{Li}$ ions leave electrons and deintercalate from the cathode into the electrolyte and get absorbed by the negatively charged anode through the external charger.

$\mathrm{LiCoO}_{2}$ and graphite are two of the typical host materials for the cathode and the anode of Li-ion batteries, respectively. Both possess layered structures that $\mathrm{Li}$ ions can diffuse in the $2 \mathrm{D}$ gap in between the layers. The redox reactions in a Li-ion battery are listed below.

$$
\begin{gathered}
\mathrm{LiCoO}_{2} \underset{\text { Decharge }}{\stackrel{\text { Charge }}{\longrightarrow}} \mathrm{Li}_{1-\mathrm{x}} \mathrm{CoO}_{2}+\mathrm{xLi}^{+} \\
6 \mathrm{C}+\mathrm{xLi}^{+}+\mathrm{xe}^{-} \underset{\text { Decharge }}{\stackrel{\text { Charge }}{\rightleftarrows}} \mathrm{LixC}_{6}
\end{gathered}
$$

Regardless of the electrochemical reactions and corresponding applications, intercalation compounds offer a wide range of different properties, e.g., superconductivity has been reported based on GIC or TMDC ${ }^{83-85}$ as well as quantum magnetothermal oscilations and charge density waves for GIC. ${ }^{86}$ 


\section{Theoretical Modeling}

\subsection{Many-body Schrödinger equation}

From the materials-science point of view, everyday-used materials can be described through electrons, nuclei, and electromagnetic interactions. Detailed theoretical description and prediction of materials properties requires several condensed-matter theories, some of which are still under development. A starting point for this is the equation below describing a system of $\mathrm{N}$ nuclei with $\mathbf{R}$ as their positions and $\mathbf{r}$ and $\sigma$ as the positions and spins of the electrons.

$$
\begin{gathered}
\widehat{H} \psi=E \psi, \\
\psi=\psi\left(R_{1}, R_{2}, \ldots, R_{N}, r_{1}, r_{2}, \ldots, r_{N}, \sigma_{1}, \sigma_{2}, \ldots, \sigma_{N}\right)
\end{gathered}
$$

In equation (5.1), $\hat{\mathrm{H}}$ is the time-independent non-relativistic many-body Schrödinger Hamiltonian and $\psi$ is the many-body wave-function while the spins of nuclei have been neglected. Solving the equation above for any desired system provides a full description of its properties. However, considering the extremely high number of dependent variables of this equation, typically comparable to $10^{23}$ (Avogadro's number), makes the equation practically impossible to solve. Even by assuming flawless periodicity for the system, there still remain hundreds of dependent variables keeping the equation far beyond being 
solvable. Thus, the way is to use an approximation for equation (5.1) so that it can mathematically be solved.

A first step to simplify equation (5.1) can be the Born-Oppenheimer approximation ${ }^{87}$ which is based on the assumption that $\boldsymbol{R}$ and $\boldsymbol{r}$ are separable. Thus, $\psi$ is the product of two independent electronic and nucleonic terms. The electrons move much faster than the nuclei, therefore, they are quickly adapted to the position of the nuclei, i.e.,

$$
\psi=\psi_{e}\left(r_{i}, \sigma_{i},\left\{R_{i}\right\}\right) \times \psi_{n}\left(R_{i}\right)
$$

In equation (5.3), $\left\{R_{i}\right\}$ can be considered as parameters in the determination of the electron wave-function. Based on this assumption, materials modeling commonly assumes the positions of the nuclei as fixed and focuses on solving the electronic part. The Hamiltonian for this case then becomes,

$$
\widehat{H}_{e}=\widehat{T}+\widehat{U}+\widehat{V}
$$

In equation (5.4), $\hat{T}$ is the kinetic energies of electrons while $\hat{U}$ and $\hat{V}$ are electron-electron and electron-nuclei potentials, respectively. Although the Born-Oppenheimer approximation removes the necessity of considering the nuclear term, the electronic Schrödinger equation still possesses too many dependent variables.

The most influential approach to meet this problem is "Density Functional Theory" (DFT) which started by the first theorem of Hohenberg and Kohn ${ }^{88}$ (HK). This theorem implies that the external potential ( $\mathrm{V}$ in equation (5.4)) uniquely defines the charge density $n(r)$ of the system by which the system can be fully described. This approach continues by the second Hohenberg and Kohn theorem ${ }^{88}$ which states that for any $V_{\text {ext }}(r)$, an energy functional $(E(n))$ in terms of the density $(n(r))$ can be defined for which the ground state is in its universal minimum, and that $n(r)$, which minimizes the energy functional, is the exact ground state density. Although these two theorems propose a way based on $n(r)$ to deal with the many-body Schrödinger equation and define the ground state of the system, they do not deal with the main problem that the Schrödinger equation is still a many-body problem. 


\subsection{Kohn-Sham density functional theory (DFT)}

This section briefly describes the approach known as the Kohn-Sham ansatz ${ }^{89}$ (KS). It has had so profound influence on materials modeling that Walter Kohn was awarded the Chemistry Nobel prize in 1998. Starting from equation (5.1) and considering the BornOppenheimer approximation, we reach a many-body Schrödinger equation describing an electronic system with dependent variables, or in other words, a system of interacting electrons. If we assume a second system but with non-interacting electrons, the Schrödinger equation is,

$$
(\widehat{T}+\widehat{V}) \psi\left(\boldsymbol{r}_{1}, \boldsymbol{r}_{2}, \ldots, \boldsymbol{r}_{n}\right)=\epsilon \psi\left(\boldsymbol{r}_{1}, \boldsymbol{r}_{2}, \ldots, \boldsymbol{r}_{n}\right)
$$

Since the electrons are non-interacting, the Hamiltonian would become the sum of identical single-electron Hamiltonians. In this case, the many-body wave function and energy are the products of all single-particle wave functions and the sum of all singleparticle electrons, respectively. In other words, dealing with the unsolvable many-body equation turns into the feasible problem of solving a single-particle equation. This provides a mathematical solution to the many-body problem, but from the condensedmatter-physics point of view, this non-interacting model is far from reality.

This problem has been met by the KS ansatz stating that a system of non-interacting particles exists which has the same ground state charge density as the corresponding interacting system. In this approach, the interaction of electrons is modeled through a complex local potential. This ansatz can be schematically described using a simple example of dropping tens of magnet bars inside a basket. At first, the magnets attract or repel each other until they reach an equilibrium state which is simply a large magnet, in the approximate shape of the basket holding the small magnets. The KS way of describing this basket would differ from the aforementioned explanation. The KS ansatz sees those small magnets as tens of non-magnetic bars which has no interaction in between but, experiencing a complex potential which keeps them together, as if they are magnets in that basket.

Based on this ansatz, the KS equations become, 


$$
\begin{gathered}
\left(\widehat{T}+\hat{V}_{e f f}\right) \psi(r)=\epsilon \psi(r) \\
\hat{V}_{e f f}=V_{e x t}+\int \frac{n\left(r^{\prime}\right)}{\left|r-r^{\prime}\right|} d r^{\prime}+\frac{\delta E_{x c}[n(r)]}{\delta n(r)}
\end{gathered}
$$

Equation (5.6) states the corresponding Schrödinger equation. In equation (5.7), $\widehat{V}_{\text {eff }}$ is the complex potential which contains the electron-nuclei interactions $\left(1^{\text {st }}\right.$ term), the electron-electron interactions ( $2^{\text {nd }}$ term), and a non-classical potential term related to electron interaction ( $3^{\text {rd }}$ term), the latter called exchange-correlation term. Based on the two aforementioned equations, the density is the sum of all single-particle wave functions.

$$
n(r)=\sum_{i=1}^{N}\left|\psi_{i}(r)\right|^{2}
$$

Using the first and the second HK theorems and the KS ansatz, the many-body Schrödinger equation has been simplified into solving a single-particle equation in a complex potential. Based on the KS ansatz, if we know exactly the exchange-correlation term, we have the exact ground state charge density of the system. There is no exact mathematical formulation for this term; however, the approximations have been so successful making the KS approach one of the most practical and highly influential aspects of materials science modeling.

\subsection{Exchange-correlation energy}

In order to simulate materials properties using the KS approach, we first need to define the energy functional derivation, (the last term in equation (5.7)). The most straightforward and the simplest approximation is called the local density approximation $^{89,90}$ (LDA)

$$
E_{x c}^{L D A}[n]=\int d^{3} r n(r)\left[e_{x}(n(r))+e_{c}(n(r))\right]
$$

where $e_{x}$ and $e_{c}$ are respectively the exchange and the correlation energies per electron of non-spin-polarized uniform electron gas with the same density. Despite of the simple formulation of LDA, it provides good approximations in a rather large field of 
applications in materials modeling. ${ }^{90} \mathrm{~A}$ widely used extension of LDA is called generalized gradient approximation ${ }^{91}$ (GGA) in which the local density is considered together with the local gradient.

$$
E_{x c}^{G G A}[n]=\int d^{3} r \epsilon_{x c}^{G G A}[n(r), \nabla n(r), r] n(r)
$$

There are several forms of $\epsilon_{x c}^{G G A}$ among which, one of the most successful and widely used was proposed in 1996 by Pardew, Burke, and Ernzerhof ${ }^{90-92}(\mathrm{PBE})$. The PBE exchangecorrelation potential is also used in my ab initio study of 2D MXene phases, (see Paper 4).

\subsection{KS self-consistent approach}

Solving KS equations for a system of electrons and nuclei is an iterative method to minimize the corresponding ground state energy with respect to the charge density.

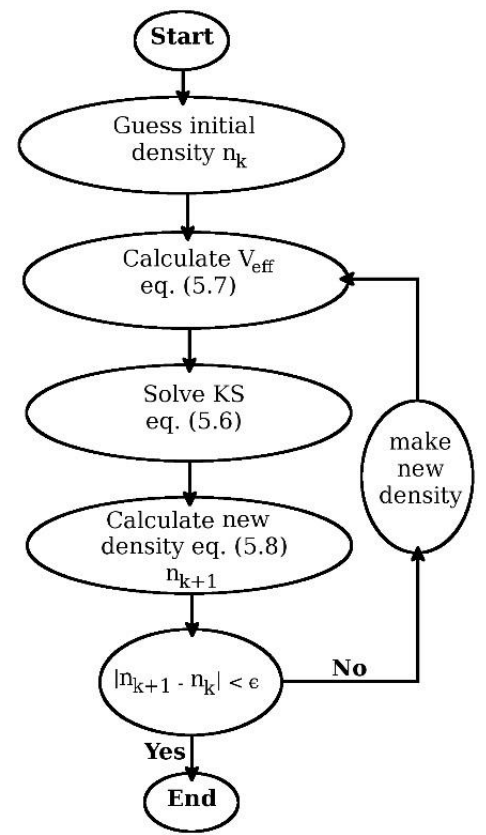

Figure (5.1). DFT-based self-consistent iteration. 
As can be seen in Figure (5.1), it starts by an initial guess for the density by which the effective potential is constructed. The next step is solving the KS equations which leads to calculating a new density. If the difference between the new and the initial densities is less than a particular preset value then the method concludes that the new density corresponds to a minimum energy of the system. If not, the iteration starts by a new density. The new density, in theory, can be the density calculated through solving the KS equations. In practice though, it is not the ideal choice with regard to the computational efficiency and cost. Depending on the method of calculation, more efficient approaches than using the original KS-derived density can be exploited for generating a new density ${ }^{93,94}$ which results in higher efficiency and lower risk of oscillating convergence.

\subsection{Relativistic effects}

Non-relativistic Schrödinger equation (5.1) discussed in the previous sections provides accurate predictions for a wide range of systems. On the other hand, for some systems, e.g., heavy elements ${ }^{87}$ or $2 \mathrm{D}$ structures (see Paper 4), relativistic phenomena like spinorbit coupling show considerable effects so that cannot be ignored. The exact approach for considering the relativistic effects is to use the Dirac equation instead of the Schrödinger equation. The Hamiltonian then is,

$$
\begin{gathered}
\widehat{H}_{D}=\left(c \alpha \cdot p+\beta m c^{2}\right) \\
\alpha_{i}=\left(\begin{array}{cc}
0 & \sigma_{i} \\
\sigma_{i} & 0
\end{array}\right), \beta=\left(\begin{array}{cc}
1 & 0 \\
0 & -1
\end{array}\right)
\end{gathered}
$$

where $p$ is the momentum operator and $\alpha_{i}$ are Pauli ${ }^{95}$ matrices. Considering $\widehat{H}_{D}$ in a spherical potential which is the case for electrostatic interaction between nuclei and electrons deep inside the core where relativistic effects are important, Dirac equation can be written as an ordinary Schrödinger equation with some extra terms. ${ }^{96}$

$$
\widehat{H}_{R}=\widehat{H}_{N R}-\frac{P^{4}}{8 m_{0}^{3} c^{2}}+\frac{\hbar^{2} \nabla^{2} V}{8 m_{0}^{2} c^{2}}+\frac{\hbar}{4 m_{0}^{2} c^{2}} \frac{1}{r} \frac{d V}{d r} l . S
$$

In equation (5.13), $\widehat{H}_{R}$ and $\widehat{H}_{N R}$ are the relativistic and non-relativistic Hamiltonians, respectively. The second term in the right-hand side of equation (5.13) is the correction 
to the kinetic energy due to the relativistic variation of mass with the velocity. The third term is the Darwin term which is the correction to the non-local interaction between electron and Coulomb field due to the shaky movement of the electron known as Zitterbewegung ${ }^{96}$ for which graphene, a single-layer carbon, is a base for study. ${ }^{97}$ The last term is called spin-orbit coupling term ${ }^{95}$ where $l$ and $S$ are angular momentum and spin operators, respectively. This term accounts for the interaction between the electron spin and the magnetic field generated by the relative motion of nuclei to electron in an atom. A manifestation of the spin-orbit coupling term is to destroy the degeneracy of oneelectron states in electronic structures of materials (see Paper 4). There are other ways to account for the aforementioned relativistic terms except for using $\widehat{H}_{R}$ instead of $\widehat{H}_{N R}, e . g$., through pseudopotentials which have been constructed considering relativistic effects and then to use them in a non-relativistic Schrödinger equation. ${ }^{87}$ 


\section{Gas Sensors}

\subsection{Catalytic reactions and catalysis-based gas sensors}

A catalyst is a chemical species which ignites or accelerates a chemical reaction while remaining intact. Catalysts are broadly used in industrial and commercial applications as well as scientific activities mainly involving catalytic reactions of gaseous or liquid substances employing solid catalysts. ${ }^{98}$ The importance of this field of research has been more emphasized in science by the 2007 Nobel Prize in chemistry awarded to Gerhard Ertl for his studies of chemical processes on solid surfaces.

Depending on the phase of the reactants and the catalyst, the catalytic reaction can be categorized into two groups: homogeneous and heterogeneous. The former refers to the case in which the reactants and the catalyst are in the same phase while in the latter, they are in different phases. In this study, a heterogeneous catalyst is investigated comprising a solid Pt layer acting as the catalyst for the oxidation reaction of carbon monoxide (CO). This type of catalytic reaction consisting of gas species reacting on a solid surface can be described within three main different mechanisms illustrated in Figure (6.1). The 
Langmuir-Hinshelwood mechanism which is shown in Figure (6.1 (a)) refers to a reaction where two species (reactants) adsorb onto the surface before the reaction. ${ }^{99}$ The reaction then takes place on the surface from which the products finally desorb. The oxidation reaction of $\mathrm{CO}$ on $\mathrm{Pt}$ surface is an example for this mechanism. ${ }^{100}$ The second mechanism is called Eley-Rideal, in which only one of the reactants adsorbs onto the surface and then reacts with another reactant which is in the gas phase. ${ }^{99}$ This mechanism is shown in Figure (6.1 (b)). Reaction of $\mathrm{NH}_{2}$ adsorbed on an appropriate metal surface with $\mathrm{NO}$ in the gas phase is an example of this mechanism. ${ }^{101}$ The third mechanism is called Marsvan Krevelen ${ }^{102}$ illustrated in Figure $(6.1$ (c)). In this mechanism, one reactant adsorbs onto the catalyst through chemical bonding. The other reactant being in the gas phase directly reacts with the first chemically bonded reactant or equivalent species on the surface (see Paper 5).

Gas sensors with the sensing based on a catalytic reaction commonly consist of a catalytic coating as a component of an electrical device. The electrical output of the device is then related to the corresponding catalytic reaction. The sensor response can be the direct result of the catalytic reaction or influenced by a side product of it (see Paper 5 for a discussion on sensing mechanism of Pt-based CO sensors).
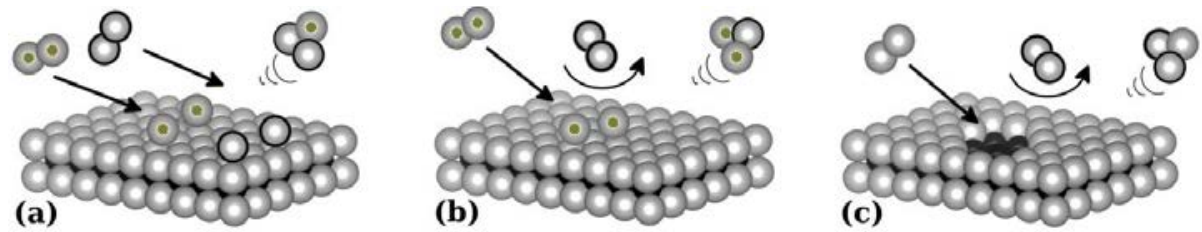

Figure 6.1. Catalytic reactions of gas species on a solid surface. (a) Langmuir-Hinshelwood. (b) EleyRideal, (c) Mars van Krevelen.

\subsection{Field-effect gas sensors}

Field-effect devices are those that use an electric field to modify their electric response such as transistors or capacitors. They can also be used as gas sensors. The sensing component is then a comprising part of the device; gate or one of the main electrodes respectively for transistors or capacitors. 

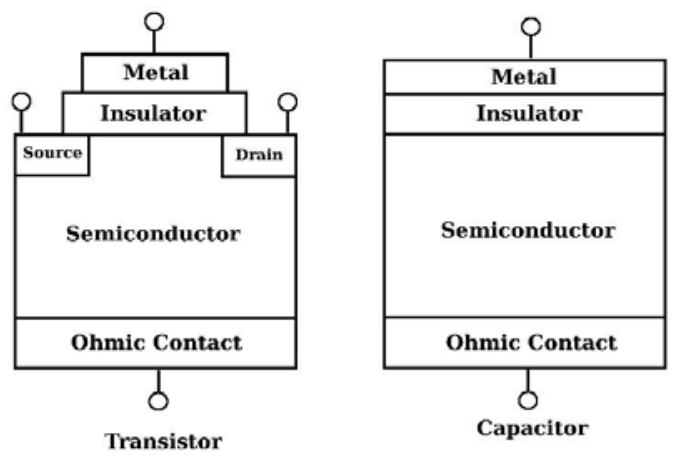

Figure 6.2. Two field-effect devices, transistor (left) and capacitor (right) used as gas sensors.

Figure (6.2) schematically illustrates two field effect devices (transistor and capacitor). For gas sensors, the combination of metal-insulator comprises the sensing component. Metals that are commonly used are $\mathrm{Pt}$, Ir, or $\mathrm{Pd}$, which possess outstanding catalytic properties. For the case of $\mathrm{Si}$ or $\mathrm{SiC}$, the insulator is $\mathrm{SiO}_{2}$ thermally grown on the surface. In case of a catalytic reaction at the surface of the metal, or at the boundary between the metal and the insulator, the configuration of the dipoles formed at the insulator/semiconductor interface is affected, which in turn can be detected by monitoring the electric response of the device.

\subsection{Characterization method}

Figure (6.2) schematically illustrates a characterization setup for gas sensors. A set of computer-controlled mass-flow controllers (MFC) generate the inlet gas flow to the sensor. Each MFC is supplied by one particular gas, controlling its flow-rate by a given set point between $0 \%$ and $100 \%$ of the MFC capacity. This provides the possibility to prepare the inlet gas with controlled composition for studying the sensor response.

The sensor is placed inside a closed chamber with an inlet from the MFC and an exhaust outlet to maintain the flow. Depending on the type of sensor, an appropriate set of devices is used to read the sensor response, e.g., a computer-controlled capacitance meter for a capacitor type sensor (see Paper 5). Analyzing the composition of the outlet gas helps characterizing a sensor from different aspects, e.g., the sensing mechanism of a sensor or 
comparison between the catalytic properties of the catalyst components of two sensors. This can be done using a mass spectrometer connected in parallel to the outlet of a sensor at operation. A part of the outlet gas enters the mass spectrometer where it gets ionized by electron bombardment. A detector then analyzes the kind and the amount of gas by sorting the molecules upon mass-to-charge ratio.

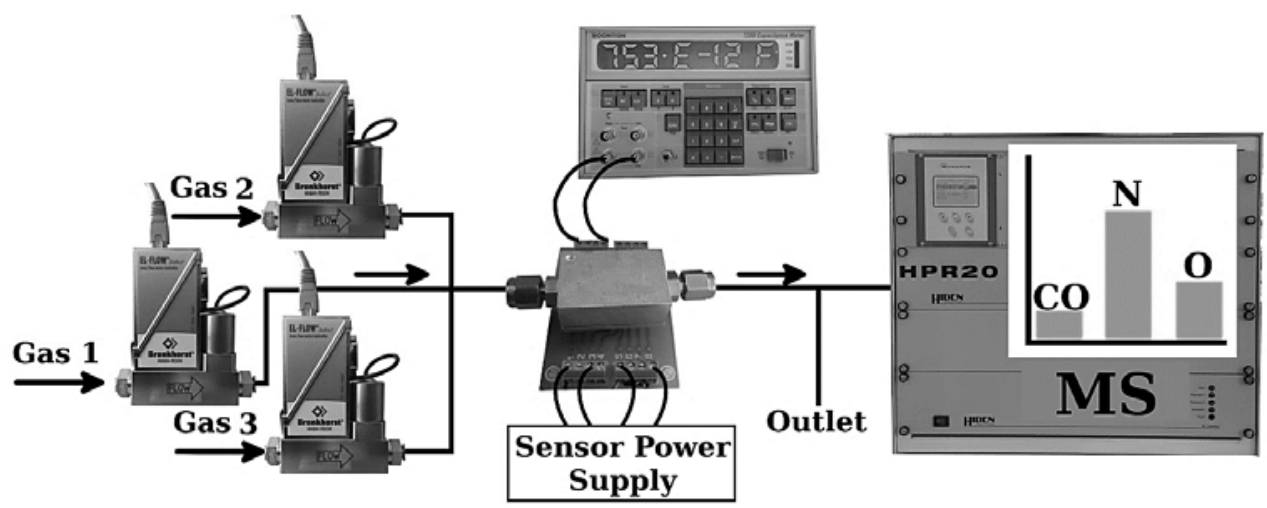

Figure 6.3 Gas sensor characterization setup. The image shows the gas flow from different mass flow controllers to the sensor chamber connected to a mass spectrometer. 


\section{Contribution to the field}

This thesis is the outcome of my PhD project on the study of $M_{n+1} A X_{n}$ phases as ohmic electrical contacts to $4 \mathrm{H}-\mathrm{SiC}$ as well studying some $2 \mathrm{D}$ materials for sensing applications. $\mathrm{Ti}_{3} \mathrm{SiC}_{2}$ is a widely-studied choice for an ohmic contact commonly synthesized from annealing of pre-deposited Ti/Al multilayers at above $900{ }^{\circ} \mathrm{C}$. This method triggers a metal/4H-SiC reaction at the contact area resulting in ohmic properties (see chapter 1 and Paper 1 for references). This approach is often referred to as "Ti-based ohmic contacts" in the absence of phase identification at the contact area. $\mathrm{Ti}_{3} \mathrm{SiC}_{2}$ together with $\mathrm{Ti}_{3} \mathrm{GeC}_{2}$ ohmic contacts have also been synthesized directly from sputter-deposition by three elemental targets continued by an annealing post-process. ${ }^{18,57,103}$

In Paper 1, I developed a novel technique for the growth of $\mathrm{Ti}_{3} \mathrm{SiC}_{2}$ ohmic contacts. This technique involves sputter-deposition of $\mathrm{Ti}$ on $4 \mathrm{H}$-SiC above $900{ }^{\circ} \mathrm{C}$ which induces a concurrent solid-state reaction to form $\mathrm{Ti}_{3} \mathrm{SiC}_{2}$ and yields as-deposited ohmic contacts. This novel technique possesses advantages over the previously reported methods. Firstly, it shows that $\mathrm{Al}$ is unnecessary in the corresponding widely-used high-temperature 
reaction of $\mathrm{Ti} / \mathrm{Al}$ multilayers on $4 \mathrm{H}-\mathrm{SiC}$ for the growth of $\mathrm{Ti}_{3} \mathrm{SiC}_{2}$. Any residual presence of $\mathrm{Al}$ in the final products may cause failure for high-temperature applications due to its low-melting point. Secondly, there is no need for a deposition system with two extra sources for $\mathrm{Si}$ and $\mathrm{C}$ for the case of direct growth, as well as the corresponding atomicflux regulations. And thirdly, there is no need for an annealing post-process. An additional advantage to the latter point is that it facilitates the growth of oxidation barriers right after the growth of $\mathrm{Ti}_{3} \mathrm{SiC}_{2}$ and prior the exposure of the contacts to air for any annealing procedure.

For many applications, resistance to long-term aging of $\mathrm{Ti}_{3} \mathrm{SiC}_{2}$ contacts at $600{ }^{\circ} \mathrm{C}$ air is required, (see a recent review article on this subject ${ }^{24}$ ). It is known that metallic stacks are generally prone to interdiffusion at $>600{ }^{\circ} \mathrm{C}$. I investigated $\mathrm{Ti}_{3} \mathrm{SiC}_{2}$ for this phenomenon and focused on the study of high-temperature interactions of $\mathrm{Ti}_{3} \mathrm{SiC}_{2}$ with noble metals. By synthesizing the structure $\mathrm{Ir} / \mathrm{Au} / \mathrm{Ti}_{3} \mathrm{SiC}_{2} / 4 \mathrm{H}-\mathrm{SiC}$, a stable ohmic contact at $600{ }^{\circ} \mathrm{C}$ air for $1000 \mathrm{~h}$ was achieved. Electron microscopy studies after the aging experiments led to the discovery of a series of novel exchange-intercalation phenomena of noble metals into $\mathrm{Ti}_{3} \mathrm{SiC}_{2}$. The novel reactions not only retained the ohmicity of my samples but also introduce a new topic of research to the materials science society: noble metal-interleaved transition metal carbides (nitrides). By recalling the fact that intercalation reactions are generally combined with van der Waals (vdW) solids, the importance and novelty of my results are further emphasized since this characteristic does not apply to my discovery.

In Paper 2, the Au-intercalation mechanism is presented. Novel $\mathrm{Ti}_{3} \mathrm{AuC}_{2}$ and $\mathrm{Ti}_{3} \mathrm{Au}_{2} \mathrm{C}_{2}$ are reported as the products of Au-intercalation into $\mathrm{Ti}_{3} \mathrm{SiC}_{2}$ as well as $\mathrm{Ti}_{3} \mathrm{IrC}_{2}$ as the product of Ir-intercalation into $\mathrm{Ti}_{3} \mathrm{Au}_{2} \mathrm{C}_{2}$. In addition, I reported $\mathrm{IrO}_{\mathrm{x}} / \mathrm{Au} / \mathrm{Ti}_{3} \mathrm{AuC}_{2} / 4 \mathrm{H}-$ $\mathrm{SiC}$ as a stable ohmic contact which remains intact after aging for $1000 \mathrm{~h}$ in $600{ }^{\circ} \mathrm{C}$ air, a property which uniquely stands out among similar reports. ${ }^{24,104-107}$ I repeated the same method with $\mathrm{Ti}_{3} \mathrm{AlC}_{2}$ and $\mathrm{Ti}_{2} \mathrm{AlC}$ films as other host choices to accommodate Au. The corresponding results which are gathered in Paper 3 led to the synthesis of novel $\mathrm{Ti}_{2} \mathrm{Au}_{2} \mathrm{C}$ as well as $\mathrm{Ti}_{3} \mathrm{Au}_{2} \mathrm{C}_{2}$ previously reported in Paper II. 
The novel exchange intercalation mechanism is a direct result of the different chemical bonding nature in $\mathrm{M}_{\mathrm{n}+1} \mathrm{AX}_{\mathrm{n}}$ phases i.e., the $\mathrm{A}$ layers are rather weakly bonded to the $\mathrm{M}_{\mathrm{n}+1} \mathrm{X}_{\mathrm{n}}$ layers, when compared to the $\mathrm{M}-\mathrm{X}$ bonding. This general fact, together with the demonstration of the exchange-intercalation phenomena in $\mathrm{Ti}_{3} \mathrm{AlC}_{2}, \mathrm{Ti}_{2} \mathrm{AlC}$, and $\mathrm{Ti}_{3} \mathrm{SiC}_{2}$ $\mathrm{M}_{\mathrm{n}+1} \mathrm{AX} \mathrm{X}_{\mathrm{n}}$ phases, indicates that my technique should be worth applying on any different $M_{n+1} A X_{n}$ phases seeking new phases.

The same property has also resulted in the successful attempt to delaminate $M_{n+1} X_{n}$ sheets from $M_{n+1} A X_{n}$ phases, named MXenes, by selective chemical etching of the A layers. This leaves the $2 \mathrm{D}$ delaminated $\mathrm{M}_{\mathrm{n}+1} \mathrm{X}_{\mathrm{n}}$ sheets, originally bonded to A layers, with chemically active surfaces being interesting for many applications, including sensors. MXenes were first reported close to the start of my studies ${ }^{108}$ while the understanding of their properties notably their interactions with ambient gas species and the corresponding surface termination atoms was limited. That led me towards theoretical simulation of properties of MXenes. I carried out ab initio studies simulating electronic and structural properties of different 2D MXene phases. The most prominent 2D material is graphene, a monolayer of carbon atoms settled in a 2D honeycomb lattice. The most important characteristic of graphene is that low energy electronic excitations in graphene act as massless Dirac fermions. Such massless charge carriers possess remarkable motility and long mean free path together with ballistic transport properties at room temperature, which are key points for the next generations of ultra-fast electronic devices as well as ultra-sensitive sensing layers. ${ }^{8,109}$ In addition, it gives rise to number of unusual physical properties at the presence of impurities or electric or magnetic fields.

In paper 4, I found that a group of MXene phases possesses conical band crossings at their Fermi level which make electrons to act as massless Dirac fermions as for graphene. By that theoretical prediction, MXenes are also introduced as a group of rare Dirac materials. MXenes are yet generally synthesized in powder form as piles of 2D sheets sticking together by vdW interactions; to be compared with graphite composed of $2 \mathrm{D}$ graphene sheets bonded together by vdW forces. By including vdW considerations to my calculations, it was predicted that the interesting Dirac-type electronic properties of Dirac MXenes are less prone to extending the dimensionality than graphene. Another comparison between Dirac MXenes and graphene was the presence of giant spin-orbit 
splitting in the Dirac points which is three orders of magnitude larger caused by the considerably larger mass of transition metals than carbon atoms.

Application of MXene in the sensor area would still benefit from basic research on optimizing and understanding terminations at realistic conditions. Closer to applications, I investigated instead a more studied 2D material for sensor applications (Paper 5): a monolayer (ML) of iron oxide grown of Pt. The growth of ML metal oxides on metals substrates has a long history in materials science and chemistry and has led to modifications of a number of surface chemical properties of the substrates when compared to their bare counterparts. One, which is related to my studies, is improvement of the catalytic properties of Pt for $\mathrm{CO}$ oxidation reactions. An obstacle for industrial applications of such results is that the corresponding standard Pt substrate (or any other materials used as the support) for this technique, is highly oriented single-crystalline bulk pieces which is in contrast to almost all industrial applications where porous polycrystalline supported films are common choices. In Paper 5, I bridged the gap between the concept of ML growth of metal oxides and industrial requirements by the study of ML iron oxide grown on polycrystalline porous Pt films supported on oxidized 4H-SiC. The approach was developed so that a realistic model for sensor and catalysts applications could be achieved.

I found that the ML coated Pt films had acquired enhanced catalytic properties over CO oxidation reactions manifested as a low-temperature shift for the ignition of $\mathrm{CO}$ oxidation. That is the same result as for ML iron oxide grown on single crystal $\mathrm{Pt}$ substrates. This result is used in my study for fabrication of metal oxide semiconductor capacitor devices (MOS) with iron oxide coated Pt as the catalytically active surface. The CO sensing properties of such devices were then compared to identical MOS devices but without the ML. I found a correlation between the electric responses of the MOS devices and the chemical properties of the surface of Pt, being either bare or ML coated. The correlation was then reported as a simple and functional technique for in-situ mapping of the chemical properties of the ML iron oxide-coated surfaces which basically requires highly sophisticated ex-situ techniques such as photo electron spectroscopy. In addition, a high stability for the monolayer coated surfaces at sensing working conditions is 
reported which further show the high functionality of my results for real-world catalysts and sensors.

My findings presented improved techniques as well as novel materials-science-related discoveries related to functional materials for contacts and gas sensors. By shedding light onto the growth of $\mathrm{Ti}_{3} \mathrm{SiC}_{2}$ on $4 \mathrm{H}-\mathrm{SiC}$, I improved its growth method for ohmic contacts. By the discovery of the novel noble metal exchange-intercalation reactions for $M_{n+1} A X_{n}$ phases, I then presented stable ohmic contacts for gas sensors intended for high temperature applications. That is in addition to the discovery of a number of new phases and the emergence of novel noble metal intercalated $M_{n+1} A X_{n}$ phases. My theoretical prediction of the existence of massless electrons in a number of 2D Dirac MXenes further highlights their importance for experimental studies while together with other theoretical reports nominated them for potential candidates for ultra-sensitive 2D sensing layers. And finally, by presenting the high functionality of 2D MLs of iron oxides for realistic sensing applications, I introduced the relatively pure-science concept of ML growth of metal oxides as a highly applied field for industrial sensors and catalysts. Moreover, I introduced the MOS model platform as a cheap and in operando characterization technique for catalysts, fuel cells, and sensor, the importance of which being more clear when recalling the commonly sophisticated characterization methods used in surface science experiments. 


\section{References}

${ }^{1}$ J.B. Casady and R.W. Johnson, Solid. State. Electron. 39, 1409 (1996).

${ }^{2}$ M. Andersson, R. Pearce, and A. Lloyd Spetz, Sensors Actuators B Chem. 179, 95 (2013).

${ }^{3}$ J. Andersson, M. Antonsson, L. Eurenius, E. Olsson, and M. Skoglundh, Appl. Catal. B Environ. 72, 71 (2007).

${ }^{4}$ Z. Darmastuti, C. Bur, P. Möller, R. Rahlin, N. Lindqvist, M. Andersson, A. Schütze, and A.L. Spetz, Sensors Actuators B Chem. 194, 511 (2014).

${ }^{5}$ E. Comini, G. Faglia, and G. Sberveglieri, editors, Solid State Gas Sensing (Springer US, Boston, MA, 2009).

${ }^{6}$ E. Comini, Anal. Chim. Acta 568, 28 (2006).

${ }^{7}$ M. Penza, C. Martucci, and G. Cassano, Sensors Actuators B Chem. 50, 52 (1998).

${ }^{8}$ R. Pearce, T. Iakimov, M. Andersson, L. Hultman, A.L. Spetz, and R. Yakimova, Sensors Actuators B Chem. 155, 451 (2011).

${ }^{9}$ N. Barsan and U. Weimar, J. Electroceramics 7, 143 (2001).

${ }^{10}$ J.B. Casady and R.W. Johnson, Solid. State. Electron. 39, 1409 (1996).

${ }^{11}$ S.E. Saddow and A. Agarwal, Advances in Silicon Carbide Processing and Applications (Artech House, Incorporated, 2004).

${ }^{12}$ B.W.Frazier, Eport of an Examination of Crystals Furnished by Mr. E. G. Acheson, President of the Carborundum Company (1893), pp. 287-289.

${ }^{13}$ P.R. Van Loan, Am. Mineral. 52, 946 (1967).

${ }^{14}$ V. Stefan and E. V Zharikov, Crystal and Epitaxial Growth (Stefan University Press, 2002).

${ }^{15}$ M. Andersson, R. Pearce, and A. Lloyd Spetz, Sensors Actuators B Chem. 179, 95 (2013).

${ }^{16}$ T. Marinova, A. Kakanakova-Georgieva, V. Krastev, R. Kakanakov, M. Neshev, L. Kassamakova, O. Noblanc, C. Arnodo, S. Cassette, C. Brylinski, B. Pecz, G. Radnoczi, and G. Vincze, Mater. Sci. Eng. B 46, 223 (1997).

${ }^{17}$ F. Roccaforte, F. La Via, V. Raineri, L. Calcagno, and P. Musumeci, Appl. Surf. Sci. 184, 295 (2001).

${ }^{18}$ K. Buchholt, R. Ghandi, M. Domeij, C.-M. Zetterling, J. Lu, P. Eklund, L. Hultman, and A.L. Spetz, Appl. Phys. Lett. 98, 042108 (2011).

${ }^{19}$ B.J. Johnson, J. Appl. Phys. 95, 5616 (2004).

${ }^{20}$ T. Jang, L.M. Porter, G.W.M. Rutsch, and B. Odekirk, Appl. Phys. Lett. 75, 3956 (1999).

${ }^{21}$ L.M. Porter and R.F. Davis, Mater. Sci. Eng. B 34, 83 (1995).

${ }^{22}$ A.V. Kuchuk, M. Guziewicz, R. Ratajczak, M. Wzorek, V.P. Kladko, and A.

Piotrowska, Microelectron. Eng. 85, 2142 (2008).

${ }^{23}$ F. Roccaforte, F. La Via, V. Raineri, L. Calcagno, and P. Musumeci, Appl. Surf. Sci. 184, 295 (2001).

${ }^{24}$ Z. Wang, W. Liu, and C. Wang, J. Electron. Mater. (2015).

${ }^{25}$ H. Fashandi, V. Ivády, P. Eklund, A.L. Spetz, M.I. Katsnelson, and I.A. Abrikosov, (n.d.). 
${ }^{26}$ M.W. Barsoum and M. Radovic, Annu. Rev. Mater. Res. 41, 195 (2011).

${ }^{27}$ P. Eklund, M. Beckers, U. Jansson, H. Högberg, and L. Hultman, Thin Solid Films 518, 1851 (2010).

${ }^{28}$ A.K. Geim and K.S. Novoselov, Nat. Mater. 6, 183 (2007).

${ }^{29}$ J.N. Coleman, M. Lotya, A. O’Neill, S.D. Bergin, P.J. King, U. Khan, K. Young, A. Gaucher, S. De, R.J. Smith, I. V Shvets, S.K. Arora, G. Stanton, H.-Y. Kim, K. Lee, G.T. Kim, G.S. Duesberg, T. Hallam, J.J. Boland, J.J. Wang, J.F. Donegan, J.C.

Grunlan, G. Moriarty, A. Shmeliov, R.J. Nicholls, J.M. Perkins, E.M. Grieveson, K. Theuwissen, D.W. McComb, P.D. Nellist, and V. Nicolosi, Science 331, 568 (2011).

${ }^{30}$ M. Ghidiu, M.R. Lukatskaya, M.-Q. Zhao, Y. Gogotsi, and M.W. Barsoum, Nature 516, 78 (2014).

${ }^{31}$ J. Halim, M.R. Lukatskaya, K.M. Cook, J. Lu, C.R. Smith, L.-Å. Näslund, S.J. May,

L. Hultman, Y. Gogotsi, P. Eklund, and M.W. Barsoum, Chem. Mater. 26, 2374 (2014).

${ }^{32}$ M. Naguib, O. Mashtalir, J. Carle, V. Presser, J. Lu, L. Hultman, Y. Gogotsi, and M.W. Barsoum, ACS Nano 6, 1322 (2012).

${ }^{33}$ M. Naguib, V.N. Mochalin, M.W. Barsoum, and Y. Gogotsi, Adv. Mater. 26, 992 (2014).

${ }^{34}$ M. Naguib, V.N. Mochalin, M.W. Barsoum, and Y. Gogotsi, Adv. Mater. 26, 992 (2014).

${ }^{35}$ J. Halim, K.M. Cook, M. Naguib, P. Eklund, Y. Gogotsi, J. Rosen, and M.W. Barsoum, Appl. Surf. Sci. 362, 406 (2016).

${ }^{36}$ M. Khazaei, M. Arai, T. Sasaki, C.-Y. Chung, N.S. Venkataramanan, M. Estili, Y. Sakka, and Y. Kawazoe, Adv. Funct. Mater. 23, 2185 (2013).

${ }^{37}$ Z.C. Feng, SiC Power Materials: Devices and Applications (Springer, 2004).

${ }^{38}$ E.H. Rhoderick, IEE Proc. I Solid State Electron Devices 129, 1 (1982).

${ }^{39}$ J. Bardeen, Phys. Rev. 71, 717 (1947).

${ }^{40}$ A.M. Cowley and S.M. Sze, J. Appl. Phys. 36, 3212 (1965).

${ }^{41}$ Z. Wang, S. Tsukimoto, M. Saito, K. Ito, M. Murakami, and Y. Ikuhara, Phys. Rev. B 80, 245303 (2009).

${ }^{42}$ Z. Wang, M. Saito, S. Tsukimoto, and Y. Ikuhara, Adv. Mater. 21, 4966 (2009).

${ }^{43}$ Z. Wang, S. Tsukimoto, M. Saito, and Y. Ikuhara, Phys. Rev. B 79, 045318 (2009).

${ }^{44}$ Y. Gao, Y. Tang, M. Hoshi, and T.. Chow, Solid. State. Electron. 44, 1875 (2000).

${ }^{45}$ M. Li, A.C. Ahyi, X. Zhu, Z. Chen, T. Isaacs-Smith, J.R. Williams, and J. Crofton, J. Electron. Mater. 39, 540 (2010).

${ }^{46}$ S.Y. Han, K.H. Kim, J.K. Kim, H.W. Jang, K.H. Lee, N.-K. Kim, E.D. Kim, and J.-L. Lee, Appl. Phys. Lett. 79, 1816 (2001).

${ }^{47}$ C. Hallin, R. Yakimova, B. Pécz, A. Georgieva, T. Marinova, L. Kasamakova, R.

Kakanakov, and E. Janzén, J. Electron. Mater. 26, 119 (1997).

${ }^{48}$ B. Pécz, L. Tóth, M.A. di Forte-Poisson, and J. Vacas, Appl. Surf. Sci. 206, 8 (2003).

${ }^{49}$ M.R. Jennings, A. Pérez-Tomás, M. Davies, D. Walker, L. Zhu, P. Losee, W. Huang, S. Balachandran, O.J. Guy, J.A. Covington, T.P. Chow, and P.A. Mawby, Solid. State. Electron. 51, 797 (2007).

${ }^{50}$ J. Crofton, L. Beyer, J.R. Williams, E.D. Luckowski, S.E. Mohney, and J.M. Delucca, Solid. State. Electron. 41, 1725 (1997). 
${ }^{51}$ S.E. Mohney, B.A. Hull, J.Y. Lin, and J. Crofton, Solid. State. Electron. 46, 689 (2002).

${ }^{52}$ M. Gao, S. Tsukimoto, S.H. Goss, S.P. Tumakha, T. Onishi, M. Murakami, and L.J. Brillson, J. Electron. Mater. 36, 277 (2007).

${ }^{53}$ S. Tsukimoto, K. Nitta, T. Sakai, M. Moriyama, and M. Murakami, J. Electron. Mater. 33, 460 (2004).

${ }^{54}$ B.J. Johnson, J. Appl. Phys. 95, 5616 (2004).

${ }^{55}$ J. Crofton, P.A. Barnes, J.R. Williams, and J.A. Edmond, Appl. Phys. Lett. 62, 384 (1993).

${ }^{56}$ J. Crofton, L. Beyer, J.R. Williams, E.D. Luckowski, S.E. Mohney, and J.M. Delucca, Solid. State. Electron. 41, 1725 (1997).

${ }^{57}$ K. Buchholt, P. Eklund, J. Jensen, J. Lu, A.L. Spetz, and L. Hultman, Scr. Mater. 64, 1141 (2011).

${ }^{58}$ Y. Martynova, M. Soldemo, J. Weissenrieder, S. Sachert, S. Polzin, W. Widdra, S. Shaikhutdinov, and H.-J. Freund, Catal. Letters 143, 1108 (2013).

${ }^{59}$ J.E. Greene, Appl. Phys. Rev. 1, 041302 (2014).

${ }^{60}$ K.S. Krane, Modern Physics (Wiley, 2012).

${ }^{61}$ J. Poortmans and V. Arkhipov, Thin Film Solar Cells: Fabrication, Characterization and Applications (Wiley, 2006).

${ }^{62}$ K. Page, M. Wilson, and I.P. Parkin, J. Mater. Chem. 19, 3819 (2009).

${ }^{63}$ E. Budke, J. Krempel-Hesse, H. Maidhof, and H. Schüssler, Surf. Coatings Technol. 112, 108 (1999).

${ }^{64}$ A.A. Voevodin, C. Muratore, and S.M. Aouadi, Surf. Coatings Technol. 257, 247 (2014).

${ }^{65}$ H. Pedersen, S. Leone, O. Kordina, A. Henry, S. Nishizawa, Y. Koshka, and E. Janzén, Chem. Rev. 112, 2434 (2012).

${ }^{66}$ D.M. Mattox, Handbook of Physical Vapor Deposition (PVD) Processing (Elsevier Science, 2010).

${ }^{67}$ R.. Horng, D.. Wuu, L.. Wu, and M.. Lee, Thin Solid Films 373, 231 (2000).

${ }^{68}$ J. Birch, T. Joelsson, F. Eriksson, N. Ghafoor, and L. Hultman, Thin Solid Films 514, 10 (2006).

${ }^{69} \mathrm{~K}$. Wasa, Handbook of Sputter Deposition Technology: Fundamentals and Applications for Functional Thin Films, Nano-Materials and MEMS (William Andrew, Incorporated, 2012).

${ }^{70}$ O. Auciello, J. Engemann, and N.A.T.O.S.A. Division, Multicomponent and Multilayered Thin Films for Advanced Microtechnologies: Techniques, Fundamentals and Devices: Techniques, Fundamentals, and Devices (Springer Netherlands, 1993).

${ }^{71}$ H.H. Rose, J. Electron Microsc. (Tokyo). 58, 77 (2009).

${ }^{72}$ P.E.J. Flewitt and R.K. Wild, Physical Methods for Materials Characterisation (Institute of Physics Pub., 1994).

${ }^{73}$ I. Miccoli, F. Edler, H. Pfnür, and C. Tegenkamp, J. Phys. Condens. Matter 27, 223201 (2015).

${ }^{74}$ (n.d.).

${ }^{75}$ M.S. Dresselhaus, editor, Intercalation in Layered Materials (Springer US, Boston, MA, 1986). 
${ }^{76}$ W. Müller-Warmuth and R. Schöllhorn, editors, Progress in Intercalation Research (Springer Netherlands, Dordrecht, 1994).

${ }^{77}$ M.B. Dines, Mater. Res. Bull. 10, 287 (1975).

${ }^{78}$ A.P. Legrand and S. Flandrois, editors, Chemical Physics of Intercalation (Springer US, Boston, MA, 1987).

${ }^{79}$ K.J. Koski, J.J. Cha, B.W. Reed, C.D. Wessells, D. Kong, and Y. Cui, J. Am. Chem. Soc. 134, 7584 (2012).

${ }^{80}$ M.S. Islam and C.A.J. Fisher, Chem. Soc. Rev. 43, 185 (2014).

${ }^{81}$ C. Eames, A.R. Armstrong, P.G. Bruce, and M.S. Islam, Chem. Mater. 24, 2155 (2012).

${ }^{82}$ M. Yoshio, R.J. Brodd, and A. Kozawa, editors, Lithium-Ion Batteries (Springer New York, New York, NY, 2009).

${ }^{83}$ T.E. Weller, M. Ellerby, S.S. Saxena, R.P. Smith, and N.T. Skipper, Nat. Phys. 1, 39 (2005).

${ }^{84}$ F.R. Gamble, F.J. Disalvo, R.A. Klemm, and T.H. Geballe, Science 168, 568 (1970).

${ }^{85}$ N. Emery, C. Hérold, J.-F. Marêché, and P. Lagrange, Sci. Technol. Adv. Mater. 9, 044102 (2016).

${ }^{86}$ S.P. Kelty and C.M. Lieber, J. Phys. Chem. 93, 5983 (1989).

${ }^{87}$ R.M. Martin, Electronic Structure: Basic Theory and Practical Methods (Cambridge University Press, 2004).

${ }^{88}$ P. Hohenberg, Phys. Rev. 136, B864 (1964).

${ }^{89}$ W. Kohn and L.J. Sham, Phys. Rev. 140, A1133 (1965).

${ }^{90}$ P. Ziesche, S. Kurth, and J.P. Perdew, Comput. Mater. Sci. 11, 122 (1998).

${ }^{91}$ J.P. Perdew and W. Yue, Phys. Rev. B 33, 8800 (1986).

92 J.P. Perdew, K. Burke, and M. Ernzerhof, Phys. Rev. Lett. 77, 3865 (1996).

${ }^{93}$ D. Johnson, Phys. Rev. B 38, 12807 (1988).

${ }^{94}$ P. Pulay, Chem. Phys. Lett. 73, 393 (1980).

${ }^{95}$ S. Gasiorowicz, Quantum Physics (Wiley, 2003).

${ }^{96}$ A. Wachter, Relativistic Quantum Mechanics (Springer Netherlands, Dordrecht, 2011).

${ }^{97}$ M.I. Katsnelson and M.I. Katsnel'son, Graphene: Carbon in Two Dimensions (Cambridge University Press, 2012).

${ }^{98}$ G. Ertl, H. Knözinger, F. Schüth, and J. Weitkamp, Handbook of Heterogeneous Catalysis, 8 Volumes (Wiley, 2008).

${ }^{99}$ B. Viswanathan, S. Sivasanker, and A. V Ramaswamy, Catalysis: Principles and Applications (Narosa Publishing House, 2002).

${ }^{100}$ M. Koper and A. Wieckowski, Fuel Cell Catalysis: A Surface Science Approach (Wiley, 2009).

${ }^{101}$ W. Kijlstra, J. Catal. 171, 219 (1997).

${ }^{102}$ G.C. Bond, R.S. of Chemistry, and G. Webb, Catalysis (Royal Society of Chemistry, 1989).

${ }^{103}$ K. Buchholt, P. Eklund, J. Jensen, J. Lu, R. Ghandi, M. Domeij, C.M. Zetterling, G. Behan, H. Zhang, A. Lloyd Spetz, and L. Hultman, J. Cryst. Growth 343, 133 (2012). 
${ }^{104}$ A. Virshup, L.M. Porter, D. Lukco, K. Buchholt, L. Hultman, and A.L. Spetz, J. Electron. Mater. 38, 569 (2009).

${ }^{105}$ R.S. Okojie, D. Lukco, Y.L. Chen, and D.J. Spry, J. Appl. Phys. 91, 6553 (2002). ${ }^{106}$ C.M. Eichfeld, M. a. Horsey, S.E. Mohney, a. V. Adedeji, and J.R. Williams, Thin Solid Films 485, 207 (2005).

${ }^{107}$ W. Daves, a. Krauss, V. Haublein, a. J. Bauer, and L. Frey, ECS J. Solid State Sci. Technol. 1, P23 (2012).

${ }^{108}$ M. Naguib, M. Kurtoglu, V. Presser, J. Lu, J. Niu, M. Heon, L. Hultman, Y. Gogotsi, and M.W. Barsoum, Adv. Mater. 23, 4248 (2011).

${ }^{109}$ F. Schedin, A.K. Geim, S. V. Morozov, E.W. Hill, P. Blake, M.I. Katsnelson, and K.S. Novoselov, Nat. Mater. 6, 652 (2007). 



\section{Papers}

The articles associated with this thesis have been removed for copyright reasons. For more details about these see:

http://urn.kb.se/resolve?urn=urn:nbn:se:liu:diva-131474 